\title{
Hippocampal tau oligomerization early in tau pathology coincides with a transient alteration of mitochondrial homeostasis and DNA repair in a mouse model of tauopathy
}

Jin Zheng ${ }^{1+}$, Mansour Akbari ${ }^{1+}$, Claire Schirmer ${ }^{2}$, Marie-Line Reynaert ${ }^{2}$, Anne Loyens ${ }^{2}$, Bruno Lefebvre ${ }^{2}$, Luc Buée ${ }^{2}$, Deborah L. Croteau ${ }^{3}$, Marie-Christine Galas ${ }^{2+}$ and Vilhelm A. Bohr ${ }^{1,3^{*+}}$ (D)

\begin{abstract}
Insoluble intracellular aggregation of tau proteins into filaments and neurodegeneration are histopathological hallmarks of Alzheimer disease (AD) and other tauopathies. Recently, prefibrillar, soluble, oligomeric tau intermediates have emerged as relevant pathological tau species; however, the molecular mechanisms of neuronal responses to tau oligomers are not fully understood. Here, we show that hippocampal neurons in six-month-old transgenic mouse model of tauopathy, THY-Tau22, are enriched with oligomeric tau, contain elongated mitochondria, and display cellular stress, but no overt cytotoxicity compared to the control mice. The levels of several key mitochondrial proteins were markedly different between the THY-Tau22 and control mice hippocampi including the mitochondrial SIRT3, PINK1, ANT1 and the fission protein DRP1. DNA base excision repair (BER) is the primary defense system against oxidative DNA damage and it was elevated in six-month-old transgenic mice. DNA polymerase $\beta$, the key BER DNA polymerase, was enriched in the cytoplasm of hippocampal neurons in six-monthold transgenic mice and localized with and within mitochondria. Pol $\beta$ also co-localized with mitochondria in human AD brains in neurons containing oligomeric tau. Most of these altered mitochondrial and DNA repair events were specific to the transgenic mice at 6 months of age and were not different from control mice at 12 months of age when tau pathology reaches its maximum and oligomeric forms of tau are no longer detectable. In summary, our data suggests that we have identified key cellular stress responses at early stages of tau pathology to preserve neuronal integrity and to promote survival. To our knowledge, this work provides the first description of multiple stress responses involving mitochondrial homeostasis and BER early during the progression of tau pathology, and represents an important advance in the etiopathogenesis of tauopathies.
\end{abstract}

Keywords: Tau oligomerization, Mitochondrial homeostasis, Polymerase beta, Oxidative stress, Tauopathies

\footnotetext{
*Correspondence: vbohr@nih.gov

Jin Zheng and Mansour Akbari are Co-first author.

Marie-Christine Galas and Vilhelm A. Bohr are Co-last author.

${ }^{1}$ Center for Healthy Aging, Department of Cellular and Molecular Medicine,

SUND, University of Copenhagen, 2200 Copenhagen N, Denmark

${ }^{3}$ Laboratory of Molecular Gerontology, National Institute on Aging, $\mathrm{NIH}, 251$

Bayview Blvd, Suite 100, Rm 06B133, Baltimore, MD 21224, USA

Full list of author information is available at the end of the article
}

(c) The Author(s). 2020 Open Access This article is distributed under the terms of the Creative Commons Attribution 4.0 International License (http://creativecommons.org/licenses/by/4.0/), which permits unrestricted use, distribution, and reproduction in any medium, provided you give appropriate credit to the original author(s) and the source, provide a link to the Creative Commons license, and indicate if changes were made. The Creative Commons Public Domain Dedication waiver (http://creativecommons.org/publicdomain/zero/1.0/) applies to the data made available in this article, unless otherwise stated. 


\section{Introduction}

The pathological aggregation of the microtubuleassociated protein tau into filaments is a histopathological hallmark of a number of neurodegenerative diseases collectively known as tauopathies, including Alzheimer disease (AD) [5, 85]. Substantial evidence suggests that the impairment of neuronal function develops before the formation of detectable levels of insoluble tangles in tauopathy mouse models [89], and that soluble oligomeric tau intermediates, formed early during the process of tau aggregation, might be the more pathological forms of tau [38, 46, 64].

In $\mathrm{AD}$ brain, neurons with tau aggregation, named neurofibrillary tangles (NFTs), can survive for decades despite progressive functional impairment [59]. This suggests that neurons that develop tau pathology may activate a response mechanism to maintain cell function and to delay cell death. The molecular mechanism of this putative cellular survival response remains largely unknown.

Mitochondria are the primary organelles for the production of the cellular energy substrate ATP. They also play a central role in other key cellular processes including cytosolic calcium buffering [23], and control of apoptosis [19]. Mitochondrial dysfunction and defects cause or are central pathological components of a number of neurodegenerative diseases [25, 92].

Mitochondrial abnormalities including aberrant mitochondrial morphology have been detected early in $\mathrm{AD}$ patients and in experimental $\mathrm{AD}$ and tauopathy model systems $[75,91]$. Moreover, there is interplay between mitochondrial dysfunction and tau pathology [25, 41, 57]. These observations suggest that interplay between mitochondrial dysfunction and tau pathology may initiate and drive the progression of tauopathies.

Mitochondrial DNA (mtDNA) is organized into structures called nucleoids in close association with the mitochondrial inner membrane [9]. Because the mitochondrial inner membrane is a major site of mitochondrial ROS production [10], mtDNA is expected to be constantly undergoing oxidative DNA damage such as 8-oxoG. DNA base excision repair (BER) is the prominent DNA repair pathway for the repair of oxidative DNA lesions [2] and probably the most important DNA repair pathway in human mitochondria $[4,78]$.

Recent reports have shown the presence of the major nuclear BER DNA polymerase, DNA polymerase $\beta$ $(\operatorname{Pol} \beta)$, in mitochondria in the brain $[65,76]$, with a likely role in mtDNA repair. 3xTgAD mice with a $50 \%$ reduction of $\operatorname{Pol} \beta\left(3 x \operatorname{Tg} A D / \operatorname{Pol} \beta^{+/-}\right)$, which also contain a mutated version of human tau, display exacerbated $A D$ phenotypes with impaired cellular bioenergetics and mitochondrial dysfunction [58, 77].
Collectively, these studies suggest that tau alterations, mitochondrial abnormalities, and BER deficiencies may interact with one another to modulate response and the development of tauopathies; however, the timing and role of these processes in the early stages of tauopathy is largely unknown.

In this study, using THY-Tau22, a mouse model of tauopathy, we show that early during tau pathology, hippocampal neurons containing oligomerized tau proteins, exhibit changes in mitochondrial structure, enhanced DNA repair activity, and mitochondrial enrichment of Pol $\beta$, but no overt cytotoxicity. These events were mostly corrected to the level of wild-type littermate mice at a later stage of tau pathology when tau oligomers are no longer detectable. We conclude that early in the progression of tau pathology in hippocampal neurons when prefibrillar tau oligomers are prominent, significant changes in mitochondrial homeostasis and DNA repair take place to counter cellular stress and to promote cell survival.

\section{Materials and methods \\ Animals}

THY-Tau22 mouse (henceforth $\mathrm{Tg}$ ), and its nontransgenic littermates $(\mathrm{Wt})$ have been described before [70]. The Tg mouse was generated with a construct containing human tau46 mutated at G272V and P301S positions and expressed under the control of Thy1.2 promoter. Tau pathology begins at 3 months of age in the subiculum and CA1 subfield, two brain regions affected early in human $\mathrm{AD}$, spreading from there to the hippocampal dentate gyrus and cortex in older animals [82]. At 6 months of age, $\mathrm{Tg}$ mice start developing spatial memory impairment and anxiety [47]. All Tg mice used in the present study were heterozygous. Nontransgenic Wt littermate mice were used as controls in all experiments. Both the THY-Tau22 and wild type littermate mice were generated from the same breeds. All mice were on C57Bl6/J background. Because no gender differences were observed in a previous report [47], data from both males and females were analyzed as a single group. In each experiment, three mice per category were analyzed (6-mo Tg, 6-mo Wt, 12-mo Tg, 12-mo Wt). All animals were kept in standard animal cages $(12 \mathrm{~h} / 12$ h light/dark cycle, at $22^{\circ} \mathrm{C}$ ), with ad libitum access to food and water. The animals were maintained in compliance with institutional protocols (Comité d'éthique en expérimentation animale du Nord Pas-de-Calais, no. 0508003). All of the animal experiments were performed in compliance with and following the approval of the local Animal Ethical Committee (agreement \#12787-2, 015,101,320,441,671 v9 from CEEA75, Lille, France), standards for the care and use of laboratory animals, and the French and European Community rules. 


\section{Immunofluorescence}

Immunofluorescence was performed as described previously [84] using the following antibodies: TOC1 (a generous gift from Dr. Nicholas Kanaan) for prefibrillar tau oligomers [64]; AT8 (Thermo Scientific) and Tau pT212 (Life Technologies) are phospho-dependent antibodies, which are present from the early to late stages of tau pathology; anti-8oxoG (Santa Cruz Biotechnology); ANT1 (ab102032, Abcam); VDAC1 (ab14734, Abcam); OGG1 (NB100-106, Novus); Polß (ab26343, Abcam); cleaved caspase 3 (9661 L, Cell Signaling Technology). DAPI was used as a chromatin counterstain. Hippocampal sections from $\mathrm{Tg}$ and Wt mice $(n=3$ for each mouse category) were acquired using an LSM 710 confocal laser-scanning microscope (Carl Zeiss). The confocal microscope was equipped with a 488-nm Argon laser, 561-nm diode-pumped solid-state laser, and a 405-nm ultraviolet laser. The images were acquired using an oil 63X Plan-APOCHROMAT objective (1.4 NA). All recordings were performed using the appropriate sampling frequency (16 bits, 1024-1024 images, and a line average of 4). Serial sections from the three-dimensional reconstruction were acquired using Z-steps of $0.2 \mu \mathrm{m}$. For each section, cellular and nuclear (based on DAPI detection) fluorescence of CA1 cells were quantified using the FIDJI macro application of ImageJ (confocal microscopy platform, IMPRT, Institut de Médecine Prédictive et de Recherche Thérapeutique, Lille). Quantification corresponds to the $\mathrm{z}$ stack of serial confocal sections covering the entire thickness of the brain section. Cellular or nuclear fluorescence was quantified in CA1 sections from three different $\mathrm{Tg}$ and three different Wt littermates mice for each age (one section per mouse). The quantification shows the mean of cellular or nuclear fluorescence values per mouse.

\section{Cell density}

Cell density was determined by counting the number of nuclei (based on DAPI staining) per surface unit in CA1 sections. Sagittal CA1 sections from 6- and 12-mo Wt and Tg mice hippocampi ( $n=3$ for each mouse category) were incubated with a solution $(2.5 \mu \mathrm{g} / \mathrm{ml}$ in PBS) of 4',6-diamidino-2-phenylindole (DAPI) (ThermoFischer) for $10 \mathrm{~min}$ at room temperature, and mounted with Vectashield/DAPI (Vector Laboratories). Nuclear DAPI fluorescence was analyzed by LSC laser scanning confocal microscopy (confocal microscopy platform, IMPRT, Institut de Médecine Prédictive et de Recherche Thérapeutique, Lille). Nuclei quantification corresponds to the $\mathrm{z}$ stack of serial confocal sections covering the entire thickness of the brain section. For each mouse category, the quantification shows the mean of nuclei per surface unit per mouse.

\section{Transmission electron microscopy}

Hippocampus from $\mathrm{Tg}$ and Wt mice $(n=3$ for each category) was fixed with paraformaldehyde $2 \%$, picric acid (1.3\% saturated in $\mathrm{H}_{2} \mathrm{O}$ ) $0.1 \%$, glutaraldehyde $1 \%$ in 0.1 $\mathrm{M}$ phosphate buffer for $72 \mathrm{~h}$ at $4{ }^{\circ} \mathrm{C}$. Tissues were rinsed 3 times in $0.1 \mathrm{M}$ phosphate buffer, post-fixed in $1 \%$ osmium tetroxide in $0.1 \mathrm{M}$ phosphate buffer for $1 \mathrm{~h}$ at room temperature, then gradually dehydrated in ethanol, and embedded in araldite (one block par hippocampus). Thin sections $(85 \mathrm{~nm})$ were made with a ultracut (Leica EM UC7), contrasted with uranyl acetate $2 \%$ and lead citrate (Reynolds). Three sections per hippocampus, at the CA1 level, were observed with Zeiss EM 900 microscope and acquisition (100-200 images from different planes for each section) realized with camera gatan (Orius SC 1000). Mitochondrial area was quantified using the FIDJI macro application of ImageJ (confocal microscopy platform, IMPRT, Institut de Médecine Prédictive et de Recherche Thérapeutique, Lille) in six representative images from three different sections per block. For each mouse category, the quantification shows the mean of mitochondrial area per mouse.

\section{Immunoelectron microscopy}

Hippocampus from $\mathrm{Tg}$ and Wt mice $(n=3$ for each category) was fixed with $0.1 \%$ glutaraldehyde and $4 \%$ paraformaldehyde in $0.1 \mathrm{M}$ Phosphate buffer for $24 \mathrm{~h}$ at $4{ }^{\circ} \mathrm{C}$. Tissues were then rinsed in $0.1 \mathrm{M}$ phosphate-buffer, dehydrated in ethanol (30 and $50 \%, 10$ min each) at $4{ }^{\circ} \mathrm{C}$, then 70 and $96 \% 10 \mathrm{~min}$ each at $-20^{\circ} \mathrm{C}$, and embedded in LRWhite resin $\left(3 \times 1 \mathrm{~h}-20^{\circ} \mathrm{C}\right.$, then overnight at $4{ }^{\circ} \mathrm{C}$ ), and polymerized under UV for 3 days at $4{ }^{\circ} \mathrm{C}$. Ultrathin sections $(85 \mathrm{~nm})$ were made with a ultracut (Leica EM UC7). After $1 \mathrm{~h}$ saturation with $0.1 \mathrm{M}$ Tris, $150 \mathrm{mM} \mathrm{NaCl}$ in $1 \% \mathrm{BSA}$ and 1\% NGS1, immunolabeling was carried out using $\operatorname{Pol} \beta$ antibody (ab26343, Abcam). Pol $\beta$ labeling was revealed with a goat antirabbit IgG gold conjugate (18 $\mathrm{nm}$ in diameter) (Jackson ImmunoResearch Laboratories). Staining of the ultrathin sections was carried out using $2 \%$ uranyl acetate in 50\% ethanol. Labeling was observed under a Zeiss EM 900 electron microscope and acquisition realized with

Table 1 Braak stages, region, age, gender, and post mortem interval of the brains used in the study

\begin{tabular}{llllll}
\hline & Braak stage & Tissue & Age & Sex & PMl $^{\mathrm{a}}$ (hours) \\
\hline Ctr\#1 & 0 & Frontal Cortex & 72 & $\mathrm{~F}$ & 72 \\
Ctr\#2 & 0 & Frontal Cortex & 47 & $\mathrm{M}$ & 39 \\
Ctr\#3 & 0 & Frontal Cortex & 74 & $\mathrm{M}$ & 48 \\
$\mathrm{AD \# 1}$ & $\mathrm{Vl}$ & Frontal Cortex & 73 & $\mathrm{~F}$ & 5 \\
$\mathrm{AD \# 2}$ & $\mathrm{Vl}$ & Frontal Cortex & 76 & $\mathrm{~F}$ & 22 \\
AD\#3 & $\mathrm{Vl}$ & Frontal Cortex & 78 & $\mathrm{M}$ & 17
\end{tabular}

${ }^{\mathrm{a}} P M I$ post mortem interval 
A

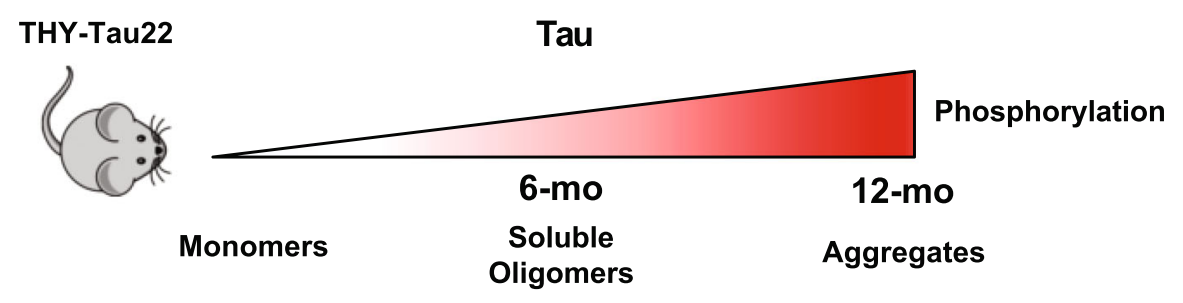

B
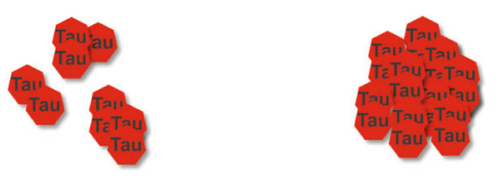

\section{CA1}

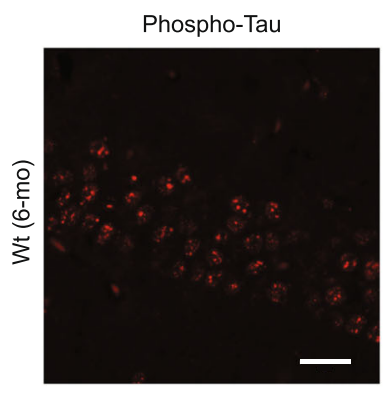

Tau oligomers

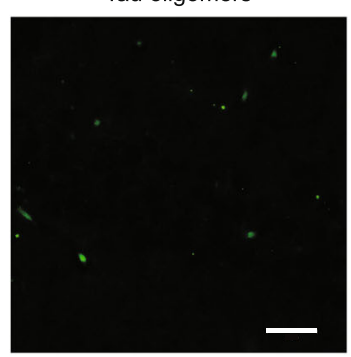

Merged + DAPI
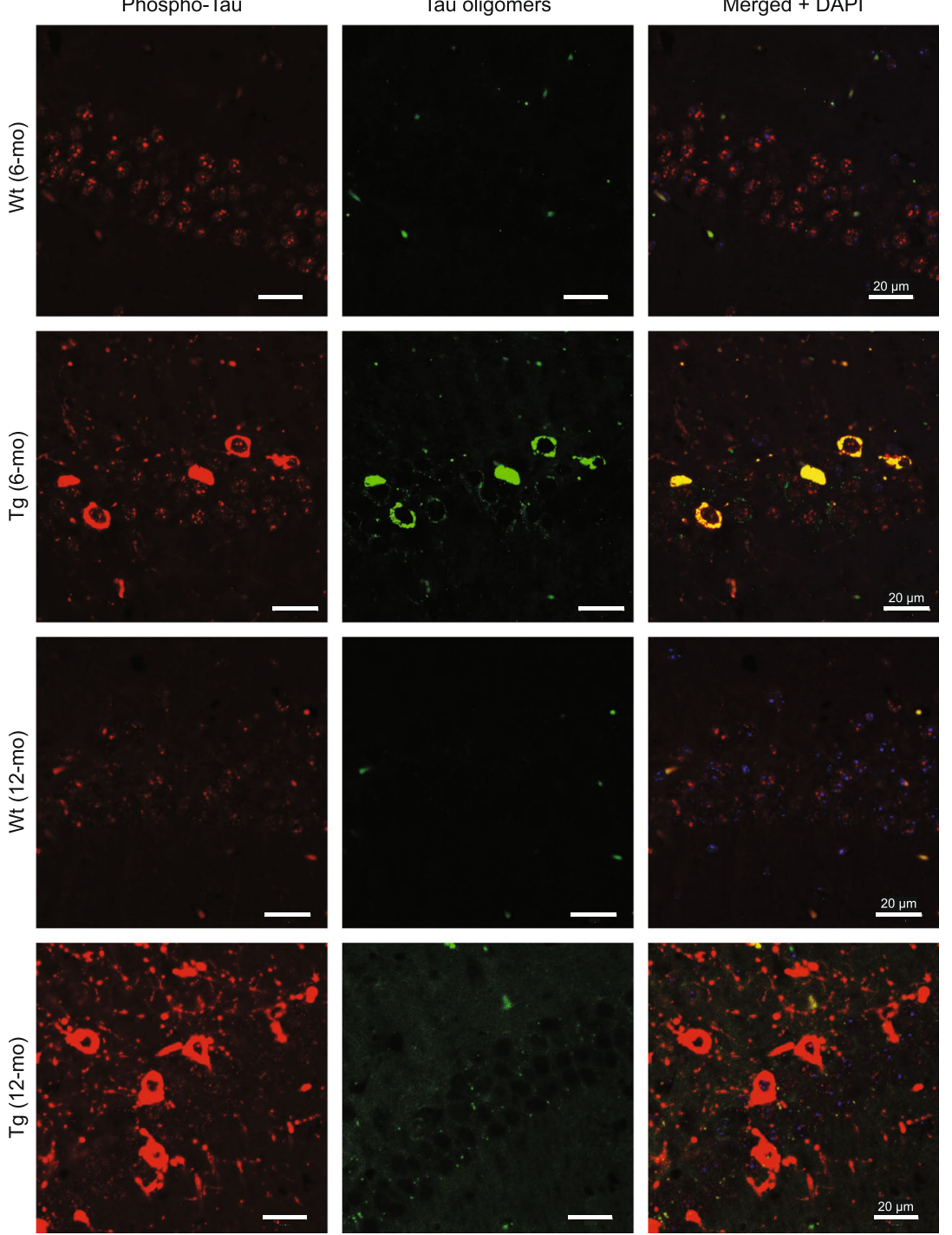

Fig. 1 (See legend on next page.) 
(See figure on previous page.)

Fig. 1 CA 1 neurons in 6-mo Tg mice are enriched with tau oligomers. a Schematic of tau pathology progression in CA1 neurons of THY-Tau22 mice. $\mathbf{b}$ Representative images of sagittal CA1 sections from 6- and 12-mo Tg and Wt mice hippocampus ( $n=3$ for each mouse category). The sections were labeled with antibodies against pathological phospho-tau (pThr212), and tau oligomers (TOC1), respectively. The sections were analyzed by laser scanning confocal microscopy (z projection). Nuclei were visualized by DAPI staining. The scale bars represent $20 \mu \mathrm{m}$

camera gatan (Orius SC 1000). Three sections per hippocampus, at the CA1 level, were observed with Zeiss EM 900 microscope and acquisition (100-200 images per section) realized with camera gatan (Orius SC 1000).

\section{Human brains}

Human brain samples were obtained from the Lille Neurobank, which was given to the French Research Ministry by the Lille Regional Hospital (CHRU-Lille) on August 14, 2008 under the reference DC- 2000-642. The Lille Neurobank fulfills criteria from the French Law on biological resources, including informed consent, ethics review committee, and data protection (article L1243-4 du Code de la Santé publique, August 2007). Frontal cortex sections from human non-dement control (Ctr) and Braak VI Alzheimer brains (AD) ( $n=3$ for each category) were used for immunofluorescence analysis (Table 1).

\section{Isolation of CA1 hippocampal region or whole hippocampus from mouse brain tissues}

Brain areas where tau pathology is localized in the $\mathrm{Tg}$ mouse brain, i.e. the CA1 subfield of the hippocampus in 6-month-old mice, or the whole hippocampus in 12month-old mice, were dissected, snap frozen in liquid nitrogen, and stored at $-80^{\circ} \mathrm{C}$. For each region, analyses were systematically compared between $\mathrm{Tg}$ and Wt mice to highlight the effect of tau pathology.

The CA1 subfield of the hippocampus from $\mathrm{Tg}$ and Wt littermates mice ( $n=3$ for each category) was isolated from whole brain hemispheres. Coronal sections $(1 \mathrm{~mm})$ from frozen mouse brain hemisphere were cut using an acrylic mouse brain matrice and matrice blades. For each frozen slice with hippocampus, the cortex was removed and the CA1 region was dissected on ice using a scalpel under a binocular loop (Leica MZ75) following anatomical landmarks (Figure S10).

\section{Protein extracts}

Mouse brain samples were lysed for $30 \mathrm{~min}$ in ice-cold RIPA buffer containing protease inhibitors and phosphatase inhibitors cocktails (Roche). Debris was removed by centrifugation at $20,000 \mathrm{~g}$ at $4{ }^{\circ} \mathrm{C}$ for $10 \mathrm{~min}$. The supernatant was used for immunoblotting.

For BER assays, the brain samples were suspended in buffer containing $20 \mathrm{mM}$ HEPES, pH 7.5, $50 \mathrm{mM} \mathrm{KCl,} 2 \mathrm{mM}$ EGTA and Complete protease inhibitor (Roche) and were homogenized. Lysates were centrifuged at $800 \mathrm{~g}$ for $10 \mathrm{~min}$ and suspended $(2 \mathrm{mg} / \mathrm{ml})$ in $20 \mathrm{mM}$ HEPES (pH 7.0), 150
mM KCl, 2 mM EGTA, 1\% (w/v) CHAPSO (Sigma), and protease inhibitor mixture and incubated at $4{ }^{\circ} \mathrm{C}$ for $1 \mathrm{~h}$ with end-over-end rotation. The lysates were centrifuged at $100,000 \mathrm{~g}$ for $1 \mathrm{~h}$, and the supernatants were collected.

\section{Western blot}

Whole cell extracts were separated in Tris-glycine SDS gels and transferred onto PVDF membrane. Each experiment was done 3-5 times. The images are shown as three technical replicates of one biological replicate. The primary antibodies used were: Actin (A5441, Sigma-Aldrich), Ac-SOD2 (Lys122, ab214675, Abcam), Caspase-3 (9962, Cell Signaling), DRP1 (8570, Cell Signaling), GAPDH (sc25778, Santa Cruz Biotechnology), LC3 (NB600-1384, Novus Biologicals), OGG1 (T1851, Epitomics), OPA1 (67, 589, Cell Signaling), PGC-1 $\alpha$ (NBP1-04676, Novus Biologicals), DRP1 (8570S, Cell Signaling), Phospho-DRP1 (Ser616, 3455, Cell Signaling), PINK1 (ab23707, Abcam), Pol $\beta$ (ABE1408, Millipore), SIRT3 (2627, Cell Signaling), SOD2 (13,194, Cell Signaling), Tau (A002401-2, Agilent), TFAM (H00007019-B01P, Abnova), VDAC1 (ab14734, Abcam), and Vinculin (ab129002, To detect OXPHOS complex assembly, we used an assembly-dependent total OXPHOS rodent antibody cocktail (ab110413, Abcam). The antibodies in the cocktail are against a subunit that is labile when its complex is not assembled.

\section{MtDNA copy number}

Total DNA (i.e. nuclear and mitochondrial) was extracted from mice brain using QIAamp DNA mini kit (Qiagen). The number of mtDNA molecules, or mtDNA copy number, was determined by quantitative-PCR using SYBR Green Supermix PCR (Bio-Rad), following the manufacturer's protocol, and StepOnePlus Real-Time PCR system (Life Technologies). Nucleotide sequence of the primers is provided in Fig.12S.

\section{MtDNA integrity analysis}

MtDNA integrity was analyzed using a PCR-based method as described previously [3, 68, 92] Briefly, PCR products were separated in agarose gel and the relative intensity of the amplicons, reflecting the level of integrity of the mtDNA templates, was measured using Image J. The nucleotide sequence of the PCR primers are shown in Fig. S12). 
A

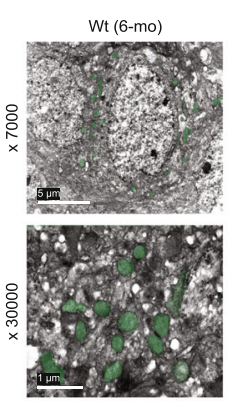

B
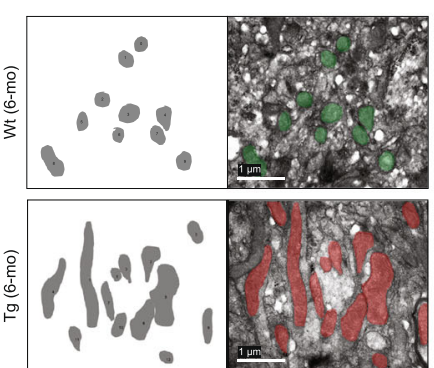

D
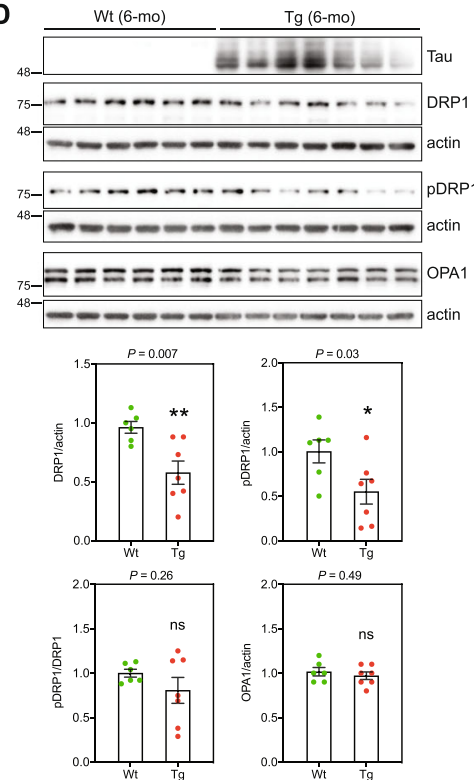

F
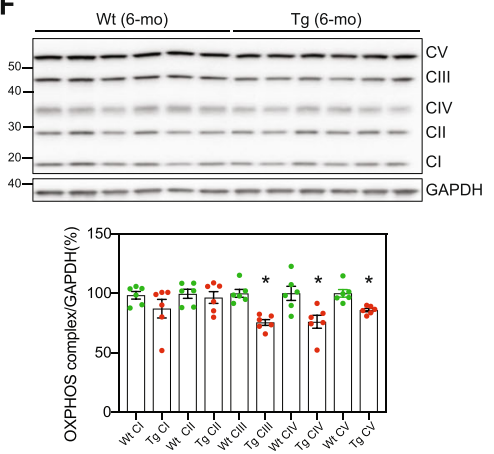

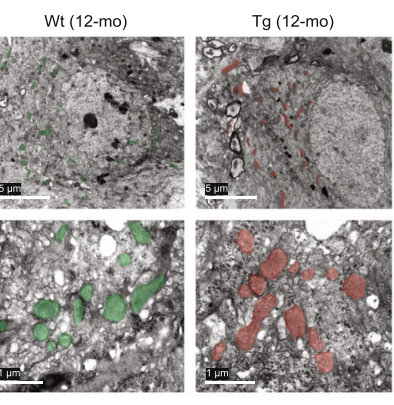

C

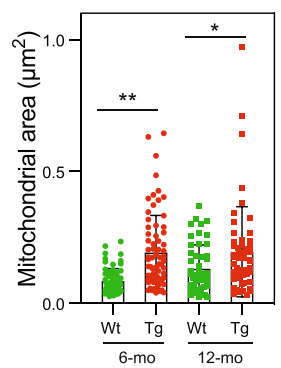

E
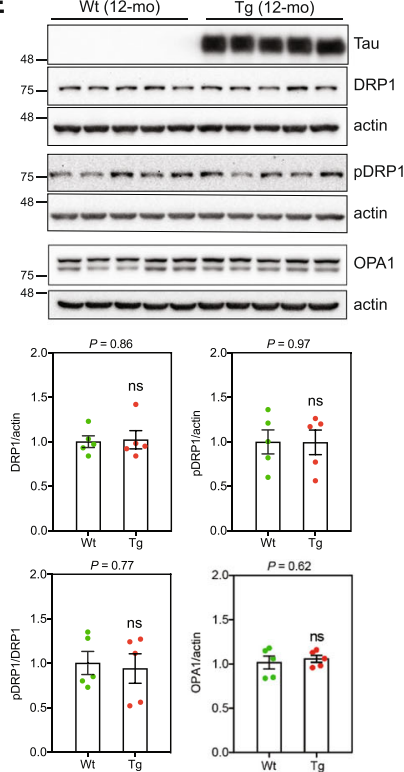

G
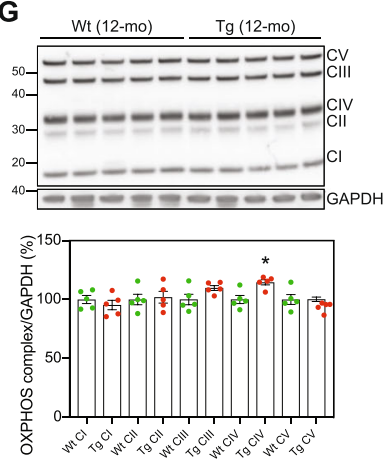

Fig. 2 (See legend on next page.) 
(See figure on previous page.)

Fig. 2 CA1 neurons in Tg mice show altered mitochondrial morphology. a Representative TEM images of CA1 sections from 6- and 12-mo Tg and Wt mice hippocampus ( $n=3$ for each mouse category). Mitochondria are highlighted by transparent colored overlay. The scale bars represent $5 \mu \mathrm{m}$ or $1 \mu \mathrm{m}$. b Illustration of the quantification of mitochondrial area from TEM images. $\mathbf{c}$ Graph shows the mean of mitochondrial area per mouse category (mitochondria: 6-mo-Wt $n=63 ; 6-\mathrm{mo}-\operatorname{Tg} n=51 ; 12-\mathrm{mo}-\mathrm{Wt} n=72$; and 12-mo $\operatorname{Tg} n=54$ ). Data is presented as mean \pm SEM ( $\left.{ }^{*} P=0.039 ;{ }^{* *} P=0.0077\right)$. $\mathbf{d}$ WB analysis of extracts from 6 -mo Wt and Tg mice CA1 (WT, $\left.n=6 ; \mathrm{Tg}, n=7\right)$, using antibodies against mitochondrial fission and fusion proteins: DRP1, pDRP1 (S616) and OPA1. Actin was used as loading control. e WB analysis of extracts from 12-mo Wt and Tg mice hippocampi (Wt, $n=5 ; \mathrm{Tg}, n=5)$. Actin or Vinculin were used as loading control. Quantifications are shown in graphs. Data is presented as mean \pm SEM ( $\left.{ }^{*} P<0.05 ;{ }^{*} P<0.01\right)$. f WB analysis of extracts from 6-mo Wt and Tg mice CA1 (Wt, $n=6 ;$ Tg, $\left.n=6\right)$ using an antibody cocktail against selected OXPHOS assembly subunits (CI: NDUFB8; CII: SDHB; CIII, MTCO1; CIV: UQCRC2; CV: ATP5A). g Graph showing the quantification results normalized to GAPDH. Data are shown as mean \pm SEM $\left({ }^{*} P<0.05\right)$

\section{AP site incision assay}

Oligonucleotide containing a synthetic analogue of an APsite 3-hydroxy-2- hydroxymethyltetrahydrofuran (shown as $\mathrm{X}$ ) was annealed to its complementary oligonucleotide. The AP-site incision reaction was carried out in $20 \mathrm{mM}$ HEPES-KOH pH 7.5, $50 \mathrm{mM} \mathrm{KCl,} 5 \mathrm{mM} \mathrm{MgCl}_{2}, 1 \mathrm{mM}$ DTT, $0.36 \mathrm{mg} / \mathrm{ml} \mathrm{BSA,} 0.5 \%$ glycerol, using $1 \mu \mathrm{g}$ extract and 2 pmol DNA substrate, at $30^{\circ} \mathrm{C}$ for $5 \mathrm{~min}$.

\section{Pol $\beta$ activity assay (gap filling assay)}

The assay for Pol $\beta$ activity was carried out as follows. The extracts $(5 \mu \mathrm{g})$ were incubated on ice for $5 \mathrm{~min}$ in $50 \mathrm{mM}$ HEPES-KOH pH 7.5, $5 \mathrm{mM} \mathrm{MgCl}_{2}, 70 \mathrm{mM} \mathrm{KCl}$, $1 \mathrm{mM}$ DTT, $50 \mu \mathrm{M}$ of each dNTP, $0.36 \mathrm{mg} / \mathrm{ml} \mathrm{BSA}$, and $0.6 \mathrm{mM}$ N-ethylmaleimide (NEM), before adding DNA substrate and initiation of DN synthesis. At the concentration used here, NEM inhibits non-Pol $\beta$ DNA polymerases [4]. Pol $\beta$ dependent DNA synthesis reaction was carried out at $37^{\circ} \mathrm{C}$ for $10 \mathrm{~min}$.

\section{8-oxo-G excision assay}

Reactions were carried out in $20 \mathrm{mM}$ Tris- $\mathrm{HCl} \mathrm{pH} \mathrm{7.5,}$ $0.1 \mathrm{M} \mathrm{NaCl}, 3 \mathrm{mM}$ EDTA, $1 \mathrm{mM}$ DTT, $0.1 \mathrm{mg} / \mathrm{ml}$ BSA, $0.5 \%$ glycerol, using $10 \mu \mathrm{g}$ extract, 1 pmol DNA substrate, at $37^{\circ} \mathrm{C}$ for $16 \mathrm{~h}$.

\section{Uracil excision assay}

Reactions were carried out in $20 \mathrm{mM}$ Tris- $\mathrm{HCl} \mathrm{pH} \mathrm{7.5,}$ $50 \mathrm{mM} \mathrm{NaCl}, 1 \mathrm{mM}$ EDTA, $1 \mathrm{mM}$ DTT, $0.1 \mathrm{mg} / \mathrm{ml}$ BSA, $5 \mu \mathrm{g}$ extract, and 5 pmol DNA substrate at $37^{\circ} \mathrm{C}$ for 15 min. Reactions were stopped by adding $1 \mathrm{M}$ piperidine and heated at $90^{\circ} \mathrm{C}$ for $20 \mathrm{~min}$ to cleave AP site generated after uracil removal.

The nucleotide sequences of all the oligonucleotides are shown in Fig. S12. DNA substrates were prepared by annealing the complementary oligos in $100 \mathrm{mM} \mathrm{NaCl}_{2}$, and $10 \mathrm{mM}$ Tris- $\mathrm{HCl}, 90^{\circ} \mathrm{C}$ for $5 \mathrm{~min}$ and slowly cooled to room temperature. All the reactions were terminated by adding loading buffer (10 mM EDTA, 95\% formamide, $0.01 \%$ bromophenol blue, $0.01 \%$ xylene cyanol) and heated at $95{ }^{\circ} \mathrm{C}$ for $5 \mathrm{~min}$. The unrepaired substrates (S), and the repair products $(\mathrm{P})$ were separated by electrophoresis in a 15\% polyacrylamide gel (19:1 acrylamide:bis), and were visualized in Typhoon 9410 (Amersham Biosciences), and quantified using Image J.

\section{Statistics}

Two-tailed, unpaired $t$-test was used for statistical analysis of WB, transmission electron microscopy, immunofluorescence, BER activity and cell density (GraphPad Prism 7). The normality of data was tested by Q-Q plotting. For WB and BER activity, each lane represents one biological replicate (i.e. one sample from one mouse), and the number of biological replicates is indicated with green and red dots on the graph. For transmission electron microscopy and immunofluorescence, each biological replicate corresponds to one mouse. The number of biological replicates is indicated in the legends.

For cell density, each biological replicate corresponds to one mouse. The number of biological replicates is indicated with green and red dots on the graph. The experimenters were not blinded. Data are presented as mean \pm SEM, ${ }^{*} P<0.05$; ${ }^{* *} P<0.01$; ${ }^{* * *} P<0.001$.

\section{Results}

Hippocampal neurons in six-month-old Tg mice are enriched with oligomerized tau

The THY-Tau22 transgenic mouse model of AD-like tauopathy (Tg) develops progressive tau hyperphosphorylation and aggregation from 3 months of age that reaches a maximum at 12 months [70]. At 6 months of age, Tg mice accumulate soluble prefibrillar tau oligomers in the cytoplasm of CA1 neurons of the hippocampus (Fig. 1a) [6].

We monitored tau pathology by immunofluorescence in CA1 neurons in sagittal sections from $\mathrm{Tg}$ and $\mathrm{Wt}$ control mice using PT212 and TOC1 antibodies, which recognize phosphorylated Thr212 and soluble oligomerized tau, respectively $[67,86]$. Hyperphosphorylated tau was detected in both six-month-old (6-mo) and 12month-old (12-mo) Tg mouse CA1 neurons (Fig. 1b). Complete co-localization of cytoplasmic signals from PT212 and TOC1 antibodies was detected in CA1 neurons from 6-mo Tg mice (Fig. 1b). Contrary to PT212, TOC1 labeling was detected in almost all neurons in 6- 


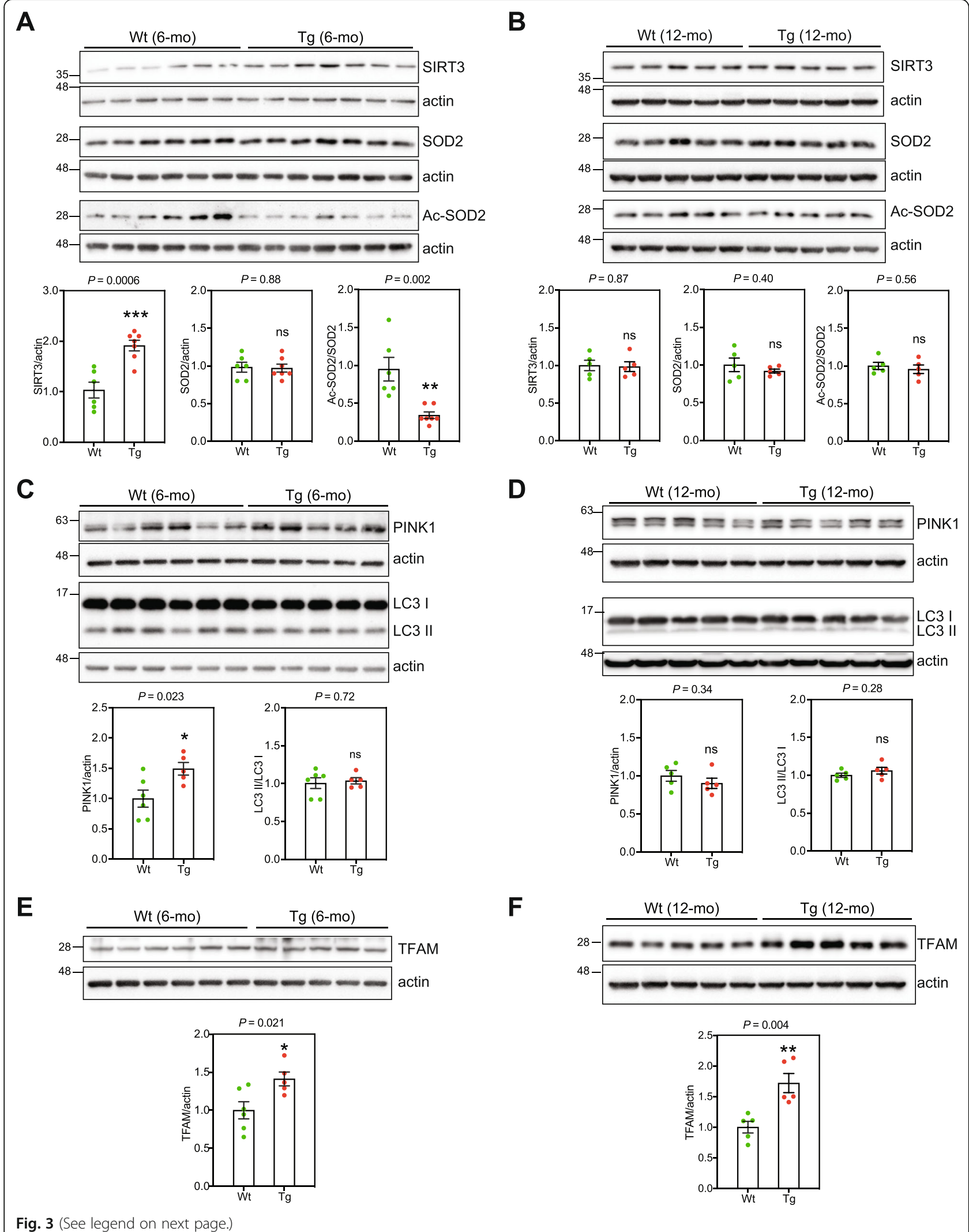


(See figure on previous page.)

Fig. 3 CA1 Tg mice undergo mitochondrial stress. a WB analysis of extracts from 6-mo Wt and Tg mice CA1 (Wt, $n=6 ; \mathrm{Tg}, n=7)$, using antibodies against SIRT3, SOD2 and acetylated SOD2. b WB analysis of extracts from 12-mo Wt and Tg mice hippocampi $(\mathrm{Wt}, n=5 ; \mathrm{Tg}, n=5)$. Data are presented as mean \pm SEM $\left.{ }^{* *} P<0.01 ;{ }^{* *} P<0.001\right)$. WB analysis of extracts from 6-mo Wt and Tg mice CA1 (Wt, $\left.n=6 ; \mathrm{Tg}, n=5\right)(\mathbf{c})$, and from 12-mo Wt and Tg mice hippocampi $(\mathrm{Wt}, n=5 ; \mathrm{Tg}, n=5)(\mathbf{d})$ for PINK1 and LC-3. Data are presented as mean \pm SEM, ${ }^{*} P<0.05$. WB analysis of extracts from 6-mo WT and Tg mice CA1 (WT, $n=5 ; \mathrm{Tg}, n=6)(\mathbf{e})$, and from 12-mo WT and Tg mice hippocampi (WT, $n=5 ; \mathrm{Tg}, n=5)(\mathbf{f})$ for TFAM. Data are presented as mean \pm SEM $\left.\left({ }^{*} P<0.05\right),{ }^{*} P<0.01\right)$. Actin was used as loading control

mo Tg mice, but was no longer detectable in 12-mo Tg mice (Fig. 1b). Thus, prefibrillar, oligomeric tau is prevalent in $\mathrm{Tg}$ mice CA1 neurons early in the course of tau pathology but is not detectable at a later stage when tau pathology has reached its maximum [70].

\section{Altered mitochondrial morphology and the abundance of OXPHOS subunits in Tg mouse hippocampal neurons}

Mitochondrial morphology is a key indicator of the state of cellular and tissue mitochondrial function and health $[1,71,92,93]$. Transmission electron microscopy (TEM) analysis revealed an enrichment of elongated hippocampal mitochondria in Tg mice compared with Wt mice, which was more pronounced in 6-mo Tg mice than in 12-mo Tg mice (Fig. 2a, b and c).

Mitochondria undergo fusion and fission resulting in elongated or smaller mitochondria, respectively. Key proteins that regulate mitochondrial fission and fusion include the cytosolic dynamin-related protein 1 (DRP1) and the mitochondrial inner membrane protein optic atrophy 1 (OPA1), respectively [13]. The level of DRP1 in CA1 from 6-mo Tg mice was significantly lower than in the CA1 from 6-mo Wt mice (Fig. 2d). Phosphorylation of DRP1 at S616 (pDRP1) promotes the recruitment of DRP1 onto mitochondria and initiates the fission process [79]. There was no difference in the ratio of pDRP1/ DRP1 suggesting that at 6 months of age, the reduced fission in $\mathrm{Tg}$ mice CA1 is caused by downregulation of DRP1 expression or increased protein turnover (Fig. 2d). Neither the amount of total DRP1, nor the level of pDRP1, were different between 12-mo Tg and Wt mouse hippocampi (Fig. 2e), suggesting that the reduced level of DRP1 in Tg mice was age dependent, occurs at early stages of tau pathology, and may contribute to the observed increased number of elongated mitochondria in Tg mouse hippocampi (Fig. 2a and b). The level of the mitochondrial inner membrane fusion protein OPA1, however, was not significantly different between $\mathrm{Tg}$ and Wt mice at any age, but a decrease was trending lower $(P=0.06)$ in 12 -mo Tg mice (Fig. $2 \mathrm{~d}$ and e).

The structure of the mitochondrial inner membrane determines the assembly and efficiency of the mitochondrial oxidative phosphorylation (OXPHOS) complexes (CI-CV) [17], linking mitochondrial morphology to mitochondrial function [93]. WB analysis showed reduced levels of CIII,
CIV, and CV in 6-mo Tg hippocampus compared with the Wt mice (Fig. 2f). In 12-mo Tg mice, however, the level of CIV was higher compared with Wt mice while the levels of CIII and CV were not (Fig. 2g).

Thus, at 6 months of age, hippocampal neurons in $\mathrm{Tg}$ mice are accumulating tau oligomers, and displaying alterations in the structure and morphology of mitochondria. These observations, link tau oligomerization to altered mitochondrial fission and to OXPHOS structure and function.

\section{Elevated mitochondrial stress response in Tg mice hippocampus}

Mitochondrial dysfunction is frequently associated with mitochondrial stress phenotypes such as increased nonenzymatic acetylation of mitochondrial proteins typically resulting in altered function of the modified proteins $[27,87,92]$. Sirtuin 3 (SIRT3) is a mitochondrial NAD ${ }^{+}$ dependent deacetylase that maintains mitochondrial homeostasis under stress conditions by removing acetylation lesions from mitochondrial proteins [15, 55, 87]. WB analysis showed that the amount of SIRT3 in CA1 from 6-mo Tg mice was markedly higher than in CA1 from Wt mice (Fig. 3a), probably in response to perpetual mitochondrial stress.

Superoxide dismutase 2 (SOD2) is an important mitochondrial antioxidant enzyme. SIRT3 deacetylates and activates SOD2 $[14,80]$. The level of acetylated SOD2, but not total SOD2, was significantly lower in 6-mo Tg mice CA1 compared with CA1 from Wt mice (Fig. 3a), consistent with higher levels of SIRT3. There were, however, no differences in the level of SIRT3, total SOD2 or acetylated SOD2 in 12-mo mice (Fig. 3b).

Mitophagy is the process of selective autophagic elimination of mitochondria. PTEN-induced putative kinase 1 (PINK1) accumulates on the outer mitochondrial membrane of damaged mitochondria with impaired membrane potential, thereby targeting the damaged mitochondria for mitophagy and lysosomal engulfment and degradation [36]. CA1 extracts from 6-mo but not from 12-mo Tg mice, contained higher amounts of PINK1 than Wt mice (Fig. 3c, d). This suggests the presence of more depolarized dysfunctional mitochondria in 6-mo Tg CA1 neurons.

Lipidated LC3 (LC3-II) facilitates substrate uptake by autophagosomes through binding to autophagy receptors. WB analysis of the ratio between nonlipidated 


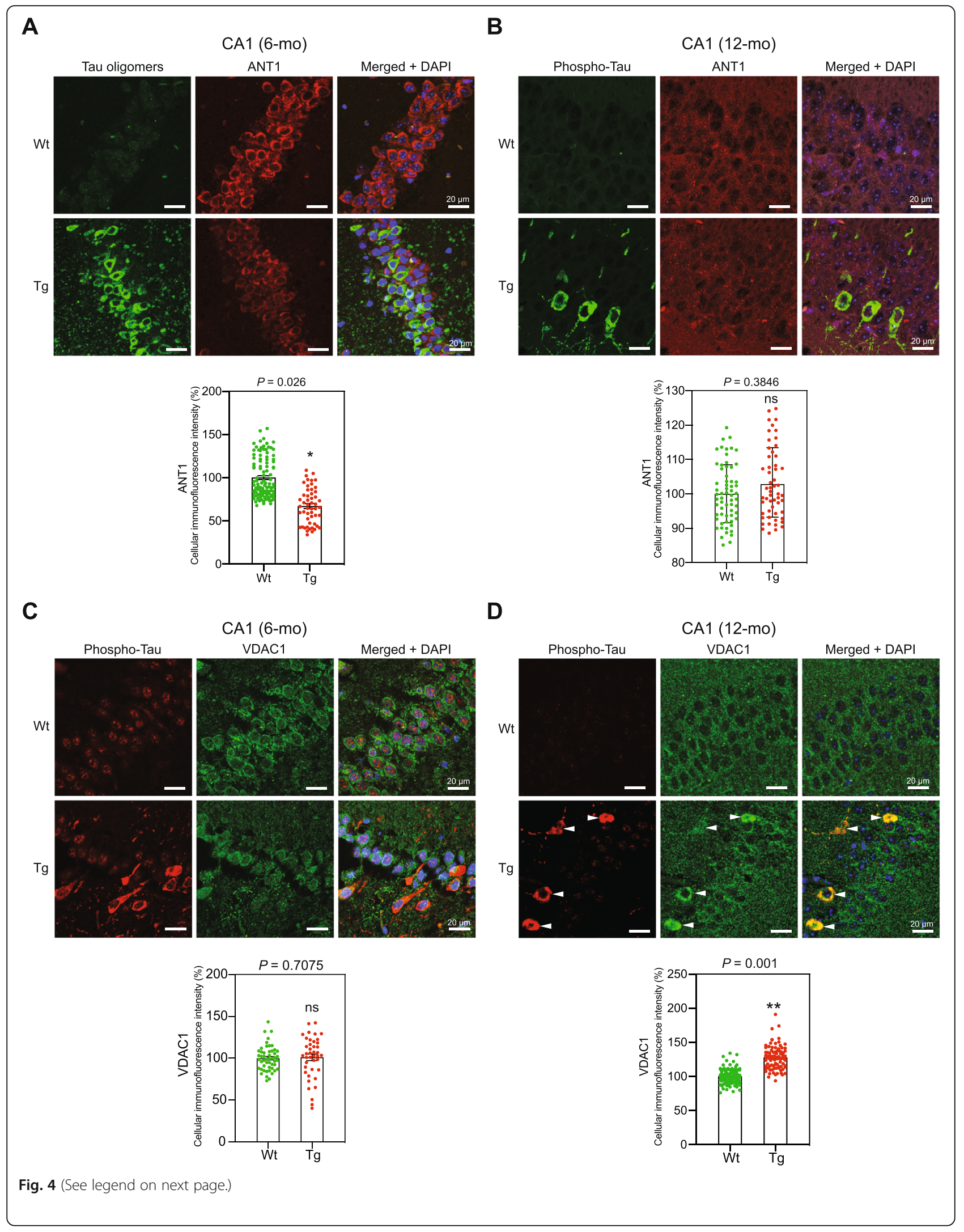


(See figure on previous page.)

Fig. 4 Altered levels of the mitochondrial proteins ANT1 and VDAC1 in Tg mice. Representative images of sagittal CA1 sections from 6- (a), and 12-mo (b), Tg and Wt mice hippocampi. The sections were labeled using TOC1 (against soluble tau oligomers) (a), pathological phosphorylated tau AT8 (against the phosphorylated tau at Ser202/Thr205) (b), and anti-ANT1 antibodies ( $n=3$ for each mouse category). Immunofluorescence signals were analyzed using laser scanning confocal microscopy (z projection). Nuclei were visualized with DAPI staining. The scale bars represent $20 \mathrm{~mm}$. The cellular ANT1 fluorescence intensity was quantified within CA1 cells from 6- and 12-mo Wt and Tg hippocampi (cells: 6-mo Wt, $n=$ 106; 6-mo Tg, $n=52 ; 12-\mathrm{mo} \mathrm{Wt}, n=63 ; 12-\mathrm{mo} \mathrm{Tg}, n=55)$. Graph shows the mean of cellular fluorescence per mouse category. Data are presented as mean \pm SEM $\left({ }^{*} P<0.05\right)$. Representative images of sagittal CA1 sections from 6- (c) and 12-mo (d) Wt and Tg mice hippocampi. The sections were labeled with antibodies against phosphorylated tau (pThr212), and VDAC1 ( $n=3$ for each mouse strain). Immunofluorescence signals were analyzed using laser scanning confocal microscopy (z projection). Nuclei were detected with DAPI staining. The scale bars represent $20 \mu \mathrm{m}$. The cellular VDAC1 fluorescence intensity was quantified within CA1 cells (6-mo Wt, $n=50 ; 6-\mathrm{mo} \mathrm{Tg}, n=41 ; 12-\mathrm{mo} \mathrm{Wt}, n=90 ; 12-\mathrm{mo} \mathrm{Tg}$, $n=118)$. Graph shows the mean of cellular fluorescence per mouse category. Data are presented as mean $\pm \operatorname{SEM}(* * P<0.01)$

LC3I/ to lapidated LC3-II has been used as a marker to monitor autophagic flux and response [31, 40]. There were no detectable differences in LC3-I/LC3-II ratio between Tg and Wt mice CA1 extracts, suggesting a similar basal autophagic flux (Fig. 3c, d).

The mitochondrial transcription factor A (TFAM) is an abundant protein with a central role in the initiation of mtDNA transcription and regulation of mtDNA replication [28]. Recently, cells from the long-lived Snell dwarf mice were shown to increase the expression of TFAM which improved mitochondrial stress response probably contributing to their increased lifespan [63]. The level of TFAM was higher in CA1 from Tg mice at both six and 12 months of age compared with Wt mice (Fig. 3e and f). WB analysis of whole CA1 extracts for VDAC1 showed no significant differences in mitochondrial mass in CA1 from 6-mo Tg and Wt mice (Suppl. Figure 1), indicating that TFAM was specifically increased in Tg mice CA1.

The transcriptional co-activator PGC- $1 \alpha$ is an important regulator of mitochondrial biogenesis [69]. There were no detectable differences in the expression of PGC$1 \alpha$ between Tg and Wt mice (Suppl. Figure 2). Notably, the activity of PGC-1 $\alpha$ is controlled by phosphorylation and acetylation $[35,61]$, detection of which often requires an immunoprecipitation step [26], which was not attempted here because of material limitation.

Thus, 6-mo Tg mice display altered expression and activity of SIRT3 with decreased ac-SOD2 and increased expression of PINK1, while TFAM expression was higher in $\mathrm{Tg}$ mice than the control mice at both ages. These results are all consistent with response to mitochondria experiencing elevated stress.

The levels of the mitochondrial protein ANT1 and VDAC1 are markedly changed in $\mathrm{Tg}$ mouse CA1 neurons with tau lesion

Adenine nucleotide translocator 1 (ANT1) is a highly abundant mitochondrial protein with important roles in the regulation of ADP/ATP exchange and mitochondrial membrane potential [8]. WB analysis did not show any differences in the ANT1 levels in lysates from 6- and 12- mo Tg and age-matched WT mice (data not shown). Immunofluorescence analysis, however, showed that the level of ANT1 was significantly reduced in 6-mo Tg mice CA1 neurons displaying high levels of tau oligomers compared with the Wt mice CA1 neurons (Fig. 4a). No differences were detected in 12-mo animals (Fig. 4b).

Voltage-dependent anion channel 1 (VDAC1), is an abundant mitochondrial outer membrane protein that plays central roles in various mitochondrial function [11]. The overall level of VDAC1 in 6-mo Tg mice CA1 was comparable to that in Wt mice (Fig. 4c, and Suppl. Figure 1). In 12-mo Tg mice CA1, however, the level of VDAC1 was significantly higher in neurons that also displayed high levels of cytoplasmic hyperphosphorylated tau compared with the rest of CA1 cells (Fig. 4d). Thus, the expression of mitochondrial proteins ANT1 and VDAC1 in Tg mice CA1 neurons are differently affected by age and the status of tauopathy.

\section{CA1 from 6-mo Tg mice contain increased copies of mtDNA molecules}

The number of mtDNA molecules in a mitochondrion correlates with the cellular energy demand of the cell and ATP production and has been used to assess the state of mitochondrial function [16, 30]. CA1 from 6-mo (Suppl. Figure 3A) but not from 12-mo Tg mice (Suppl. Figure 3B) contained higher mtDNA copy numbers compared with CA1 from the Wt mice.

There were no significant differences in ATP levels in CA1 from 6-mo Tg mice compared to CA1 from Wt mice (Suppl. Figure 4), suggesting comparable levels of ATP production and perhaps consumption despite the morphological and mtDNA copy number differences.

\section{CA1 extracts from 6-mo Tg mice display elevated BER activity}

BER is the prominent pathway for repair of oxidative DNA damage and is active in both the nucleus and mitochondria [2, 78]. To test the biochemical effects of the observed mitochondrial stress in Tg mice, we carried out BER analyses in CA1 extracts. 8-oxo-G removal and 

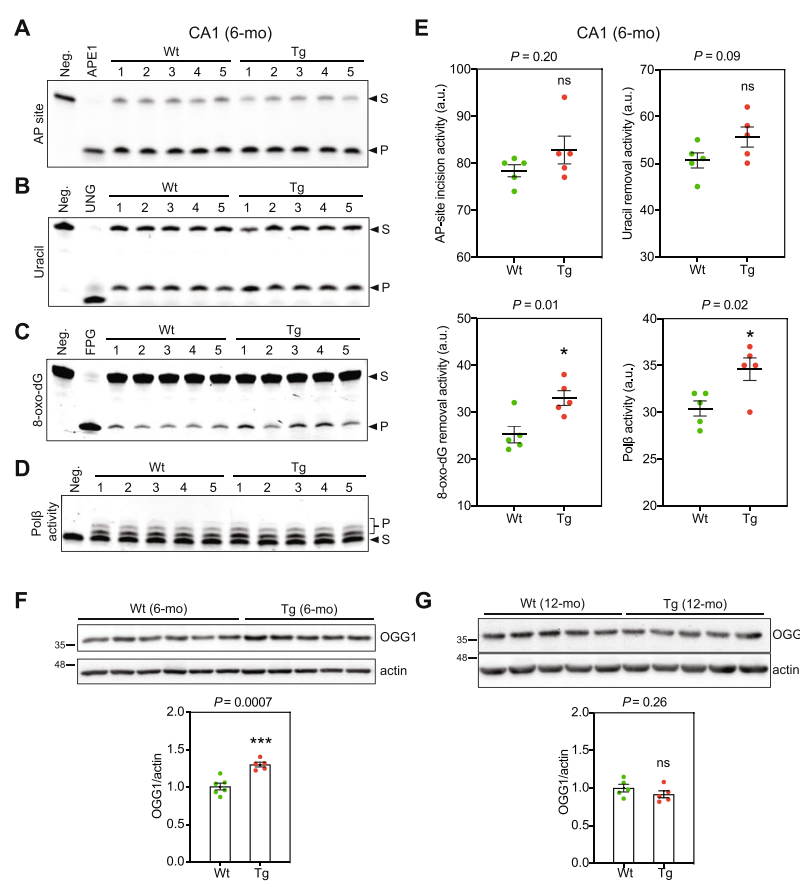

H

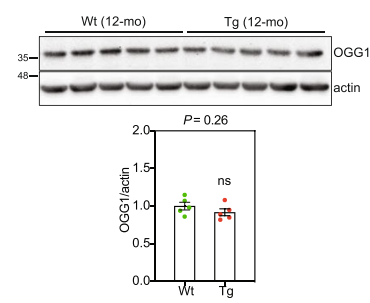

CA1 6-mo
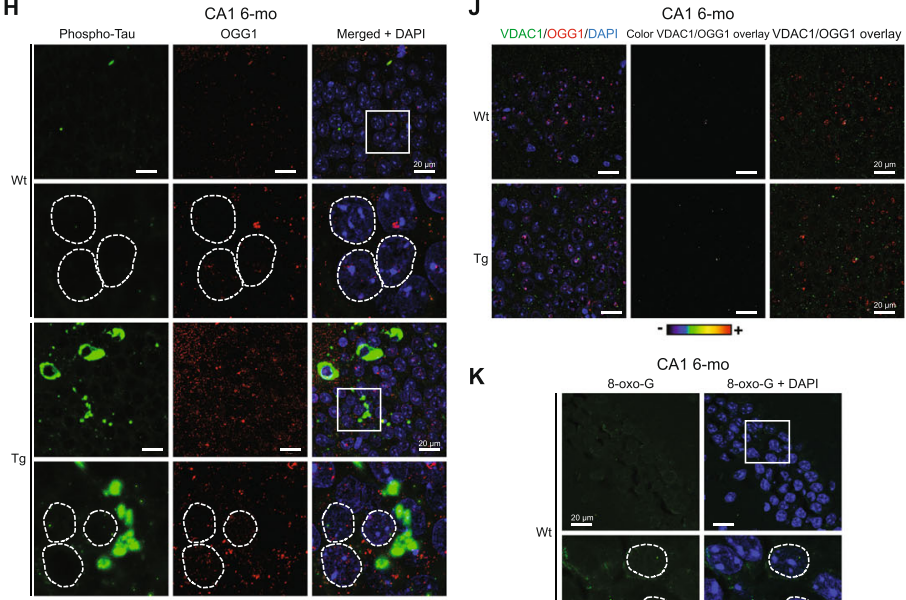

K
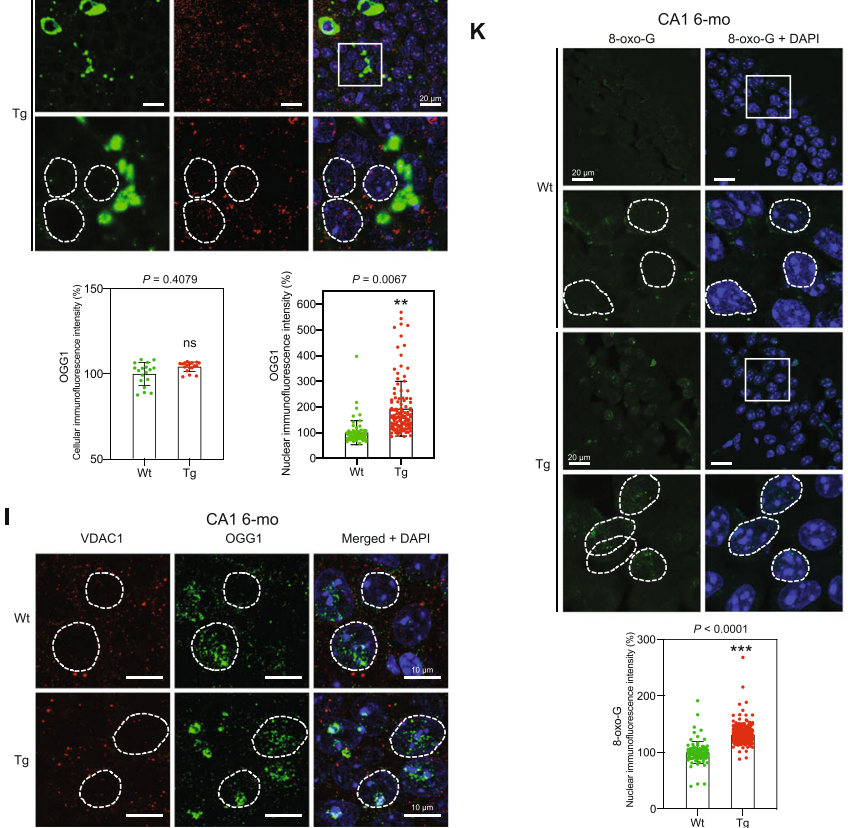

Fig. 5 (See legend on next page.) 
(See figure on previous page.)

Fig. 5 Increased levels of BER activity, 8-oxo-G base lesion, and OGG1 DNA glycosylase in CA1 neurons in 6-mo Tg mice. Biochemical analysis of BER activity in CA1 extracts from 6-mo Tg and Wt mice. a AP-site incision activity. Recombinant APE1 protein was used as a positive control. $\mathbf{b}$ Uracil removal activity. Purified recombinant UNG was used as a positive control. c 8-oxo-dG removal activity. Formamidopyrimidine DNA glycosylase (FPG) was used as a positive control. $\mathbf{d}$ Pol $\beta$ nucleotide incorporation activity. e Quantifications of A-D, data are presented as mean \pm SEM ( $\left.{ }^{*} P<0.05\right)$. WB analysis of CA1 extracts from 6-mo Wt $(n=5)$ and $\operatorname{Tg}(n=6)$ mice $(\mathbf{f})$, and hippocampus extracts from $12-\mathrm{mo}$ Wt $(n=5)$ and $\operatorname{Tg}(n=5)$ mice $(\mathbf{g})$ for OGG1. Actin was used as a loading control. Quantification results are shown in the graph below. Data are presented as mean \pm SEM $\left({ }^{* * *} P<0.001\right)$. h Representative images of sagittal CA1 sections from 6-mo Wt and Tg mice. The sections were co-labeled with AT8 and anti-OGG1 antibodies ( $n=3$ for each mouse strain). The immunofluorescence signals were analyzed by laser scanning confocal microscopy ( $z$ projection). DAPI staining was used to visualize nuclei. Representative nuclei are delimitated by white dashed lines. The scale bars represent $20 \mu \mathrm{m}$. The cellular and nuclear OGG1 fluorescence intensity was quantified within CA1 cells (cells: Wt, $n=18 ; \mathrm{Tg}, n=18$ )(nuclei: Wt, $n=68 ; \mathrm{Tg}$, $n=116)$. Graph shows the mean of cellular or nuclear fluorescence per mouse category. Data are presented as mean \pm SEM (**P<0.01). i Possible mitochondrial localization of OGG1 was determined by labeling sagittal CA1 sections from 6-mo Wt and Tg mice with anti-VDAC1 and anti-OGG1 antibodies ( $n=3$ for each mouse strain). Immunofluorescence labeling was analyzed using laser scanning confocal microscopy (single confocal section). DAPI staining was used to visualize nuclei. The scale bars represent $20 \mu \mathrm{m}$. Representative nuclei are delimitated by white dashed lines. The scale bars represent $10 \mu \mathrm{m}$. j Overlay of VDAC1 and OGG1 Immunofluorescence signals. The scale bars represent $20 \mu \mathrm{m}$. k Representative images of sagittal CA1 sections from 6-mo Wt and Tg mice hippocampi ( $n=3$ for each mouse strain). The sections were labeled with the 8-oxo-G antibody after RNAse pretreatment as described before [84] to selectively target oxidative DNA lesions (8-oxo-G). Immunofluorescence signals were analyzed using laser scanning confocal microscopy (z projection). Nuclei were detected with DAPI staining. Representative nuclei are delimitated by white dashed lines. The scale bars represent $20 \mu \mathrm{m}$. The intensity of the nuclear 8-oxo-G fluorescence signals was quantified within CA1 cells from 6-mo Wt and Tg hippocampi (nuclei: 6-mo Wt, $n=98 ; 6-\mathrm{mo} \mathrm{Tg}, n=343$ ). Graph shows the mean of cellular or nuclear fluorescence per mouse category. Data are presented as mean \pm SEM $(* * *<0.001)$. S, substrate; $P$, repair product

DNA polymerase $\beta(\operatorname{Pol} \beta)$ repair DNA synthesis activities were markedly higher in CA1 extracts from 6-mo Tg mice compared with the Wt mice (Fig. 5c, d), but not in hippocampal extracts from 12-mo $\mathrm{Tg}$ mice (Suppl. Figure 5). These results suggest a tau-dependent and age-specific increase in BER activity in CA1, perhaps as a part of the cellular response to oxidative stress.

\section{Increased levels of nuclear OGG1 and 8-oxo-G in 6-mo Tg mice hippocampal neurons}

8-oxo-guanine DNA glycosylase (OGG1) is the major enzyme for removal of 8-oxoG lesions from DNA. WB analysis showed a significantly higher amounts of OGG1 in hippocampal extracts from 6-mo but not from 12-mo $\mathrm{Tg}$ mice compared with Wt mice (Fig. $5 \mathrm{f}$ and g), corroborating the biochemical results (Fig. 5c, and Suppl. Figure 5).

Immunofluorescence analysis of CA1 sections showed significantly increased levels of OGG1 mainly in the nucleus of CA1 neurons in 6-mo Tg mice (Fig. 5h). Costaining of OGG1 and VDAC1 did not show discernable co-localization signals, suggesting the absence or very low levels of OGG1 in mitochondria in CA1 neurons in 6-mo Tg mice (Fig. 5i and j).

CA1 hippocampal neurons from 6-mo $\mathrm{Tg}$ mice showed a higher level of 8-oxo-G base lesion signal compared with Wt control mice illustrating increased oxidative DNA damage (Fig. 5k). 8-oxo-G signal was restricted to nuclei suggesting that mtDNA did not contain discernible amounts of oxidative base lesions.

Thus, 6-mo $\mathrm{Tg}$ mice CA1 hippocampal neurons undergo elevated oxidative stress. The increased 8-oxoG removal activity (Fig. 5c) and the levels of OGG1 protein (Fig. 5f) are likely part of the cellular response to increased oxidative stress.

\section{Altered level and intracellular distribution of Pol $\beta$ in 6-mo Tg mouse hippocampal neurons and human AD brain}

$\operatorname{Pol} \beta$ is a key BER protein, and likely the rate limiting one. It is predominantly a nuclear protein, but was recently detected in the mitochondria where it is likely involved in mtDNA repair $[65,76]$.

Because Pol $\beta$ activity was increased in CA1 hippocampus from 6-mo Tg mice (Fig. 5d), we examined the effect of early tau pathology on the expression and cellular localization of Pol $\beta$ within CA1 neurons. WB analysis and immunofluorescence analysis of CA1 sections showed no significant differences in Pol $\beta$ levels in, respectively, CA1 extracts and CA1 cells from Tg and WT mice (Suppl. Figure 6, Fig. 6a). However, the level of nuclear Pol $\beta$ was significantly reduced in 6-mo Tg mice (Fig. 6a). This was not observed in 12-mo Tg mice (Suppl. Figure 7).

Moreover, an increased overall cellular Pol $\beta$ fluorescence signal was observed in CA1 cells from 6-mo Tg mice with tau hyperphosphorylation (High Ptau) (Fig. 6a). Because the level of nuclear fluorescence of $\operatorname{Pol} \beta$ did not significantly change in these cells, this shows that the increased tau phosphorylation correlates with an increased level of cytoplasmic Pol $\beta$ (Fig. 6a). While the overall level of Pol $\beta$ is unchanged in Tg compared to Wt mice (Suppl. Figure 6, Fig. 6a), interestingly, Pol $\beta$ translocates from the nucleus to the cytoplasm in CA1 cells with tau hyperphosphorylation in 6-mo Tg mice.

Immunofluorescence co-labeling of $\operatorname{Pol} \beta$ and VDAC1 revealed co-localization of cytosolic Pol $\beta$ with VDAC1, suggesting that $\mathrm{Pol} \beta$ is located within or onto mitochondria in 


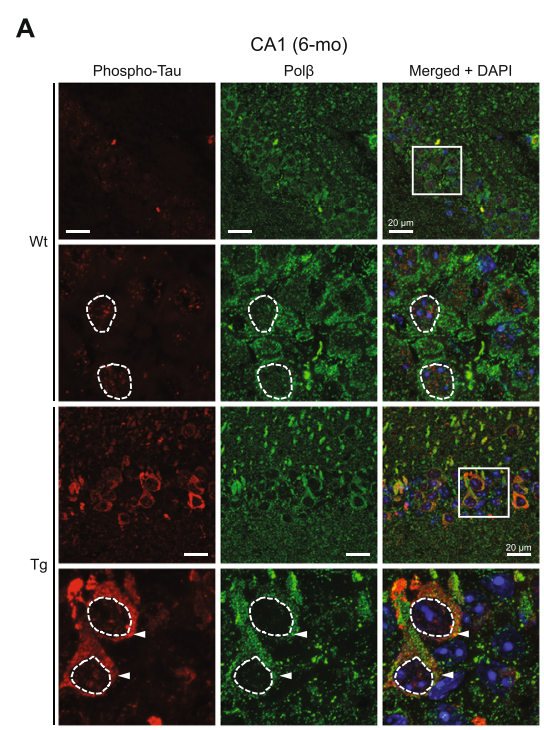

B
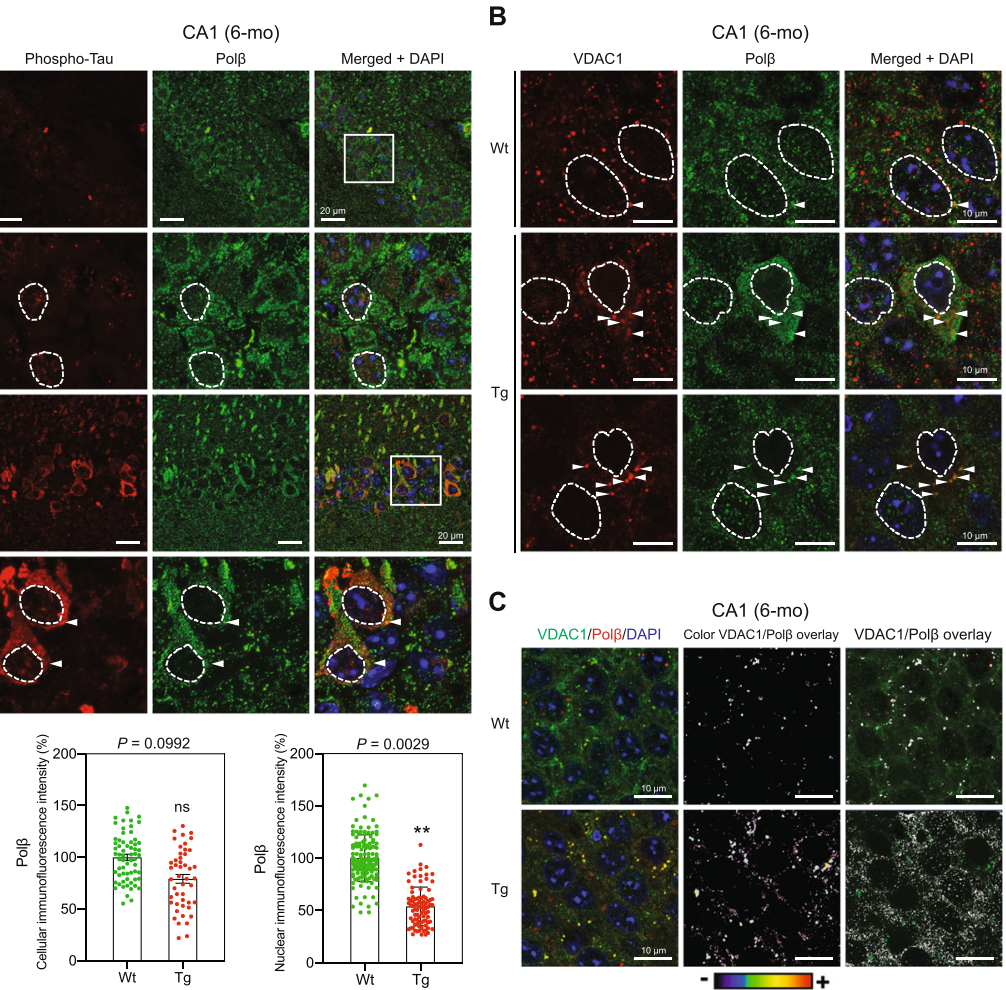

C

CA1 (6-mo)
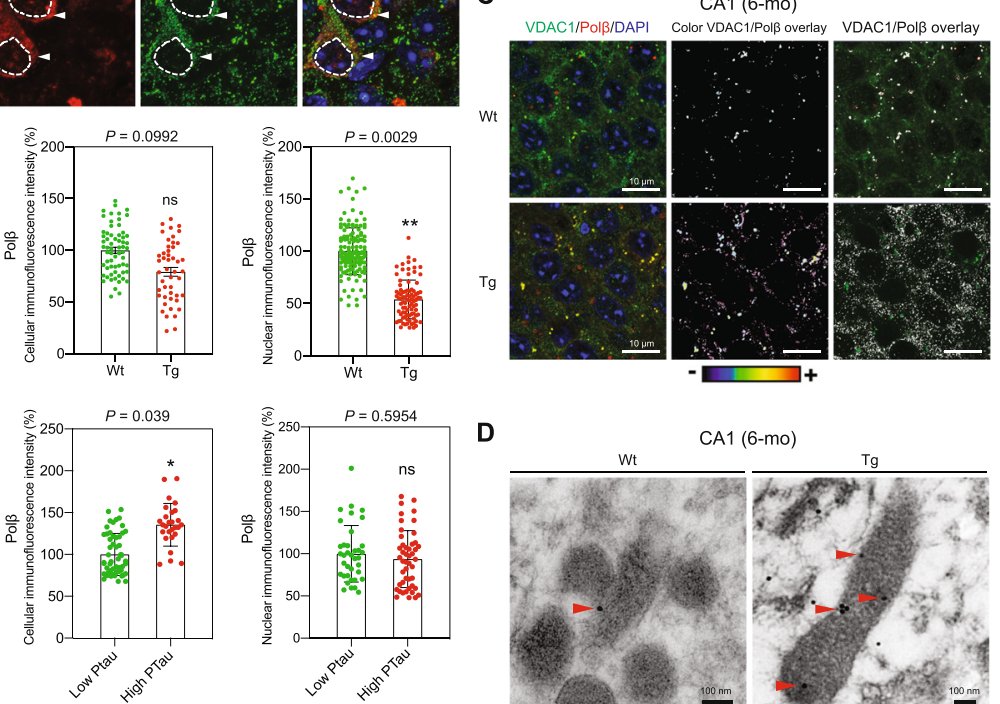

D

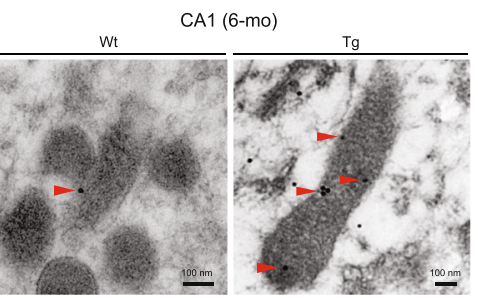

E

$\mathbf{F}$
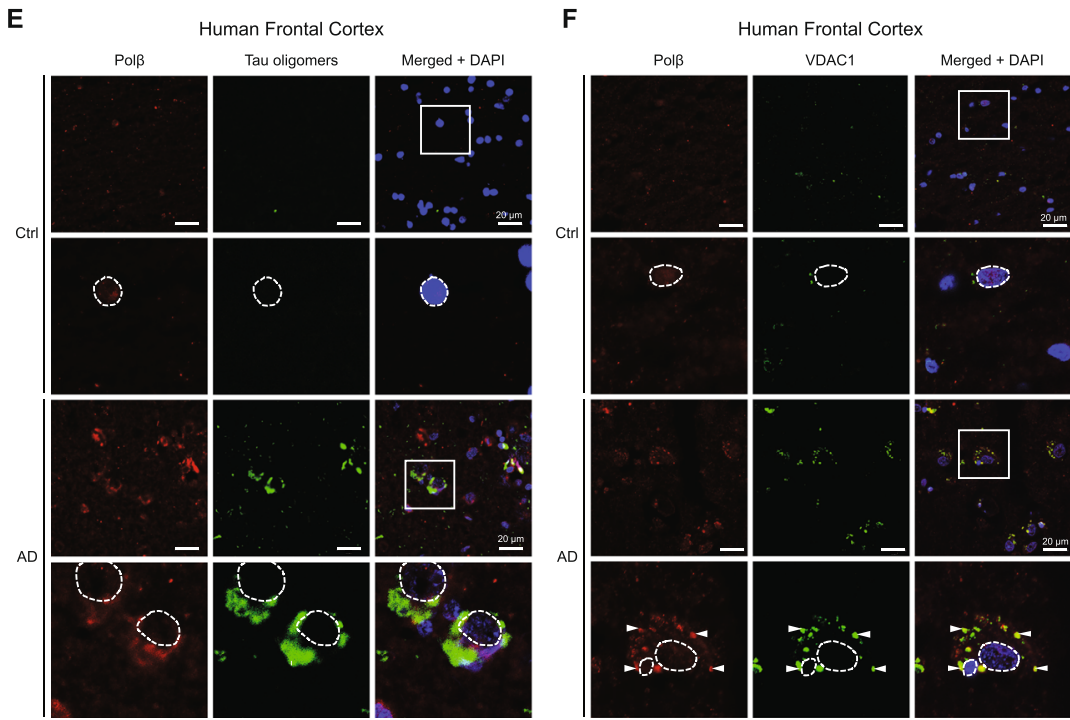

Fig. 6 (See legend on next page.) 
(See figure on previous page.)

Fig. 6 Cytoplasmic and mitochondrial accumulation of Pol $\beta$ in 6-mo Tg mice hippocampal neurons. a Representative images of sagittal CA1 sections from 6-mo Wt and Tg mice hippocampi ( $n=3$ for each phenotype). The sections were co-labeled with anti-phospho-tau (AT8), and Pol $\beta$ antibodies ( $n=3$ for each mouse category). Immunofluorescence signals were analyzed using laser scanning confocal microscopy ( $z$ projection). Nuclei were detected with DAPI staining. Representative nuclei are delimitated by white dashed lines. The scale bars represent $20 \mu \mathrm{m} .$. The intensity of the cellular and nuclear Pol $\beta$ fluorescence signals was quantified within CA1 cells from 6-mo Wt and Tg hippocampi (cells: Wt, $n=64$; $\mathrm{Tg}, n=47$; nuclei: Wt, $n=142 ; \mathrm{Tg}, n=88)$. Graph shows the mean of cellular or nuclear fluorescence per mouse category. Data are presented as mean \pm SEM $\left(* P<0.05 ;{ }^{*} P<0.01\right)$. The intensity of the cellular and nuclear Pol $\beta$ fluorescence signals was separately quantified within $C A 1$ cells from 6-mo Tg hippocampi with either high (High Ptau) or low phospho-tau (Low Ptau) levels (cells: Low Ptau $n=53$, High PTau $n=27$; nuclei Tg: Low Ptau $n=37$, High PTau $n=47)$. Data are presented as mean \pm SEM $\left(* P<0.05 ;{ }^{* *} P<0.01\right)$. The cut off value of fluorescence between high and low phospho-tau levels has been arbitrary chosen based on visual evaluation of the cytoplasmic phospho-tau labeling. b Mitochondrial localization of Pol $\beta$ was assessed by labeling sagittal CA1 sections from 6-mo Wt and Tg mice with VDAC1 and Pol $\beta$ antibodies $(n=3$ for each mouse strain). Immunofluorescence signals were analyzed by laser scanning confocal microscopy (single confocal section). The scale bars represent $10 \mu \mathrm{m}$. Representative nuclei are delimitated by white dashed lines. White arrows point VDAC1 and Pol $\beta$ co-localization. c Overlays of immunofluorescence labeling of VDAC1 and Polß. d Representative immunoelectron microscopy images of CA1 sections from 6-mo Tg and Wt mice hippocampus. The sections were labeled with Pol $\beta$ antibodies ( $n=3$ for each mouse strain). The scale bars represent $100 \mathrm{~nm}$. Red arrows point Pol $\beta$ localization. e Representative images of frontal cortex sections from human control (Ctr) and Braak VI Alzheimer frontal cortex (AD). The sections were labeled with the tau oligomer antibody, TOC1, and anti-Pol $\beta$ antibody ( $n=3$ for each category). Immunofluorescence signals were analyzed by laser scanning confocal microscopy (z projection). Nuclei were detected with DAPI staining. Representative nuclei are delimitated by white dashed lines. The scale bars represent $20 \mu \mathrm{m}$. f Immunofluorescence labeling of the same sections with antibodies against PoI $\beta$ and VDAC1 demonstrates mitochondrial localization of PoI $\beta$. Immunofluorescence signals were analyzed by laser scanning confocal microscopy (single confocal section). Nuclei were detected with DAPI staining. Representative nuclei are delimitated by white dashed lines. The scale bars represent $20 \mu \mathrm{m}$. White arrows point VDAC1 and Pol $\beta$ localization

CA1 neurons in 6-mo Tg mice (Fig. 6b and c). Immunoelectron microscopy using anti-Pol $\beta$ antibody showed increased Pol $\beta$ signals within mitochondria in 6-mo Tg mice compared to Wt (Fig. 6d, and Suppl. Fig. 8), further demonstrating the accumulation of $\operatorname{Pol} \beta$ within mitochondria in CA1 cells with hyperphosphorylated/oligomerized tau in 6mo Tg mice.

These results suggest a potential role of $\mathrm{Pol} \beta$ in mtDNA repair in CA1 cell. We tested this using a PCRbased method [68, 92]. This method, as used here, mostly detects AP-sites in DNA. There were no detectable differences in the level of mtDNA integrity in CA1 from 6-mo and 12-mo Tg and Wt mice (Suppl. Figure 9). This suggests that the enrichment of $\operatorname{Pol} \beta$ in mitochondria in the neurons with hyperphosphorylated/oligomerized tau may contribute to the preservation of the mtDNA integrity in those cells that is comparable to $\mathrm{Wt}$ mice CA1; however, this needs further investigation.

We next investigated the relevance of these findings to human tau pathology. We found specific cytoplasmic accumulation of $\operatorname{Pol} \beta$ in neurons positive for soluble tau oligomers in frontal cortex from human AD brains (Fig. 6e and Suppl. Fig. S11). Cytoplasmic Polß labeling was detected in all the cells that also showed the accumulation of tau oligomers. Co-labeling of $\operatorname{Pol} \beta$ and VDAC1 in the same brain samples highlighted strong co-localization signal (Fig. $6 \mathrm{f}$ and Suppl. Fig. S11). Thus, our results demonstrate a correlation between extra nuclear and mitochondrial localization of $\operatorname{Pol} \beta$ and the presence of soluble oligomerized tau protein in $\mathrm{Tg}$ mouse CA1 (Fig. 6a, b, c and d) and in frontal cortex from human AD brains (Fig. 6e, f and Suppl. Fig. 11).
Tau oligomerization and mitochondrial stress do not lead to significant CA1 neuronal loss

Mitochondrial dysfunction may trigger cell death by apoptosis [83]. Caspases are central mediators of neuronal apoptosis. Activated caspase- 3 has been detected in hippocampus in $\mathrm{AD}$ mouse models, and was related to increased DNA damage and neuronal death [77], but also to early synaptic dysfunction without cell death [20]. Immunofluorescence analysis of CA1 sections did not show detectable levels of activated caspase- 3 in $\mathrm{Tg}$ or in Wt mice (Fig. 7a). Rare caspase-3 activated apoptotic events may be difficult to detect. Thus, we quantified the DAPI-stained nuclei to determine the cell density in the CA1 section as a measure of cell loss. A slight but statistically significant decrease in cell density was detected in 12-mo Tg mouse CA1 compared with CA1 from 12-mo Wt mice (Fig. 7b). WB analysis showed very faint bands corresponding to the expected size of cleaved caspase- 3 in CA1 extracts from 12-mo Wt and Tg mice (Fig. 7c). Together, these results suggest that tau oligomerization and the mitochondrial alterations observed in 6-mo Tg CA1 cells do not lead to a detectable level of CA1 neuronal loss; however, at later stages of tau pathology, some neuronal loss in CA1 may take place as previously described [70]. It is noteworthy, however, that the use of a stereological tool like optimized optical fractionator would be necessary for unbiased estimation of neuronal number [33].

\section{Discussion}

In this study, we show that at early stages of tau pathology when soluble tau oligomers are prominent, 


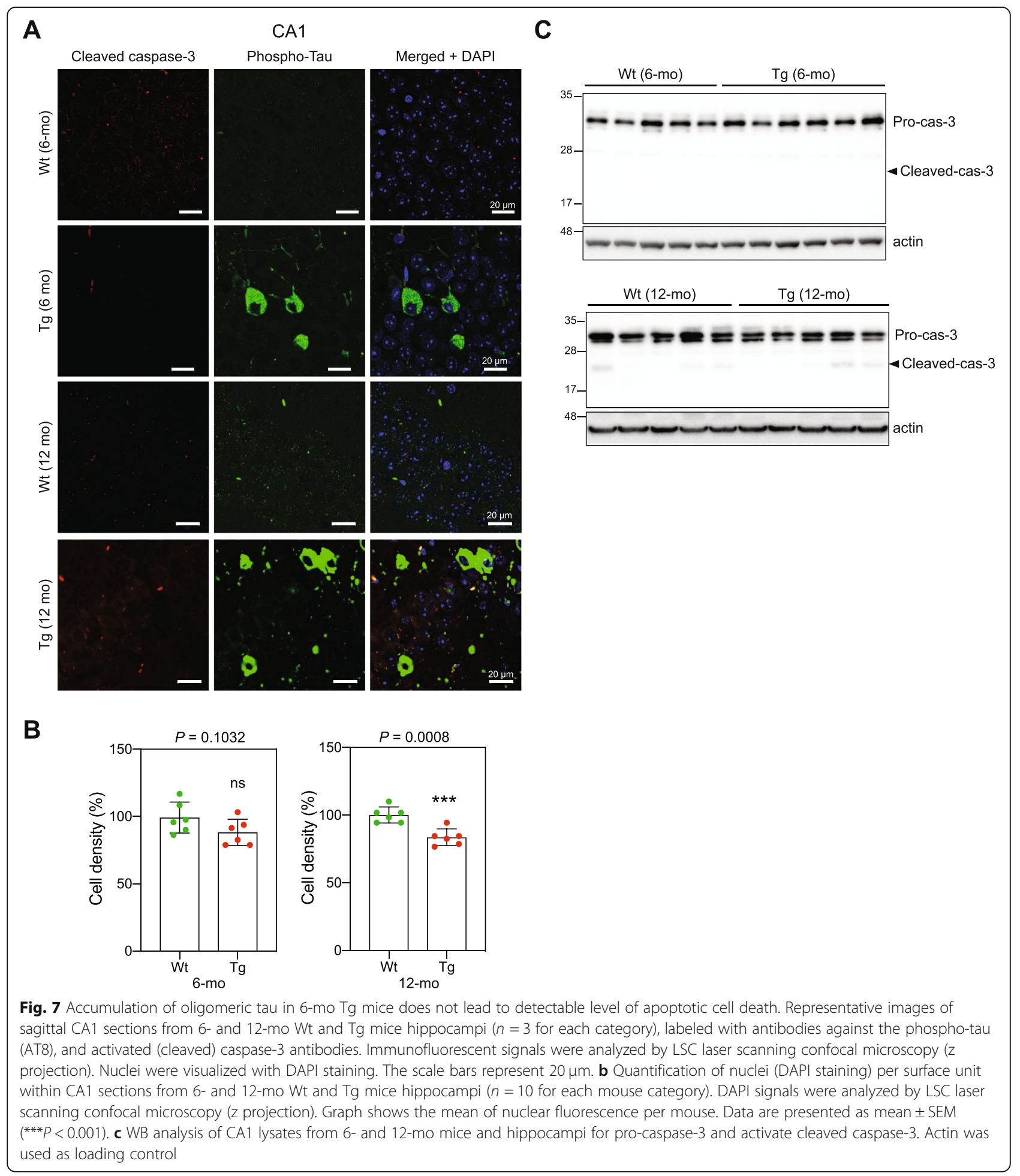

hippocampal neurons undergo significant changes in mitochondrial homeostasis, DNA repair activity, and cytosolic and mitochondrial translocation of $\mathrm{Pol} \beta$ (Fig. 8a). These events likely promote cell survival and counter cellular stress caused by tau oligomers.
Prefibrillar oligomers have emerged as the more deleterious forms of tau rather than the previously thought larger tau aggregates $[29,32,46,60,64,84]$ and other pathogenic tau species in AD [46]. In cell models, oligomeric tau intermediates have been described as neuronal 


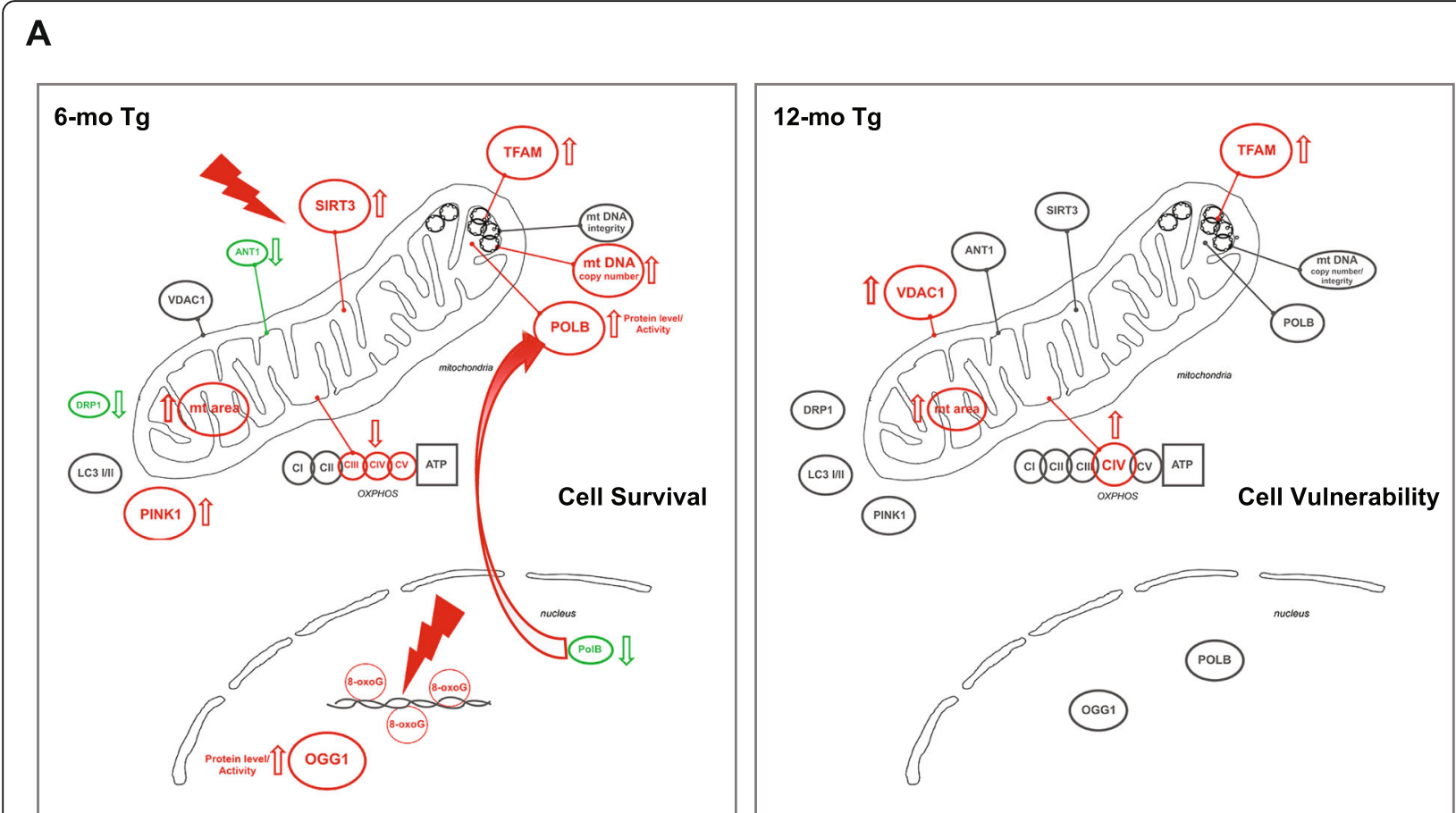

B

Tau

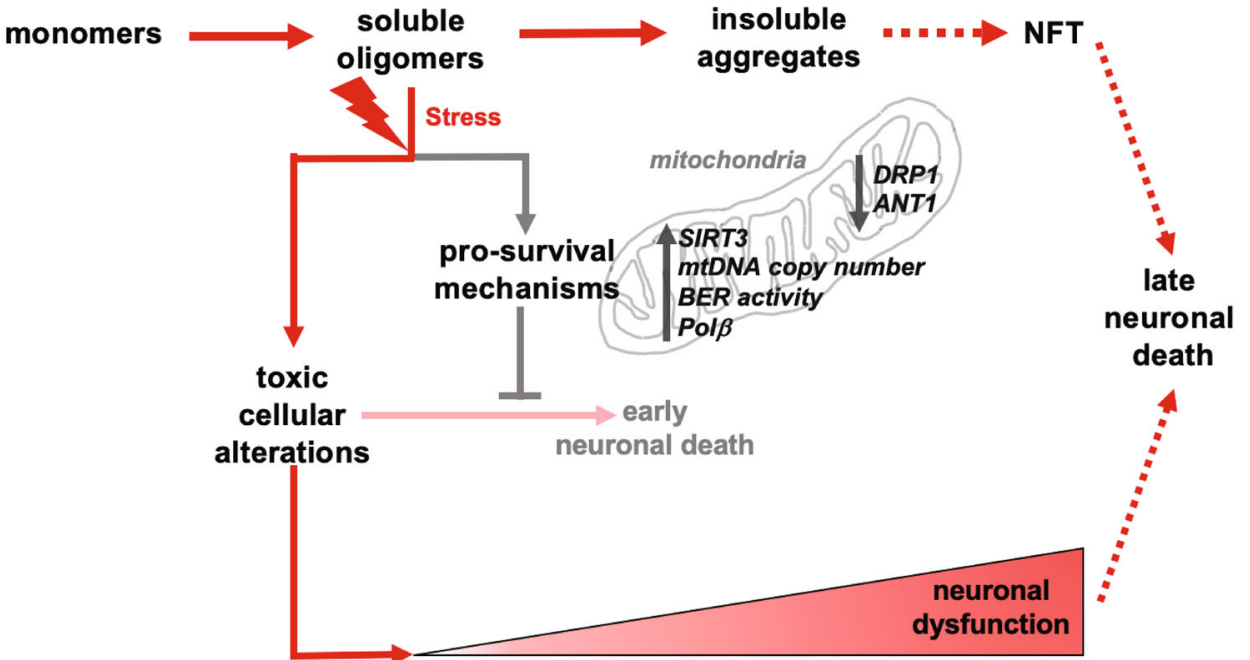

Fig. 8 a Schematic summary of mitochondrial and BER alterations in hippocampus neurons from 6- and 12-mo Tg mice detected in this study. b Schematic roles of soluble tau oligomers in disease progression

death inducers $[29,44]$. Injection of recombinant human tau oligomers into mouse hippocampus produced mitochondrial respiratory chain dysfunction, activated the pro-apoptotic protein caspase-9 and induced neurodegeneration in the CA1 region [45]. However, if endogenous soluble tau oligomers induced cell death in AD brains, neurons with insoluble aggregates and NFT should not be observed. This suggests that in human brains, neurons with tau pathology develop efficient mechanisms to counter the cell toxicity caused by soluble tau oligomers and promote neuronal survival.

Consistent with this hypothesis, our results show that CA1 neurons in 6-mo $\mathrm{Tg}$ mice with prominent 
endogenous prefibrillar tau oligomers in the cytoplasm, activate a cellular stress response and show no evidence for increased cell death.

A recent study showed that the method of tau oligomers preparation and other experimental conditions might account for the observed cytotoxicity of tau oligomers [38]. Under improved experimental conditions, tau oligomers caused synaptotoxicity, increased ROS production, and impaired calcium homeostasis, but had no overt effects on cell viability [38]. These findings are largely in line with our conclusions. We cannot, however, rule out that some populations of neurons may fail to develop effective pro-survival mechanisms against tau oligomers-induced toxicity and die, thus, contributing to early neuronal loss observed in AD.

SIRT3 is the primary mitochondrial $\mathrm{NAD}^{+}$-dependent deacetylase [52]. In stressful conditions such as excitotoxicity and high ROS production, SIRT3 maintains mitochondrial homeostasis and promotes neuronal stress resistance and survival $[21,39,66]$. Oxidative and metabolic stress modulate the expression of SIRT3 [55]. A decrease in SIRT3 protein level was linked to mitochondrial dysfunction in AD brain [48]. Increased level and activity of SIRT3 (Fig. 3a) concomitant with the enrichment of prefibrillar tau oligomers in 6-mo $\mathrm{Tg}$ mouse CA1 region, suggests that CA1 neurons are undergoing stress and activate SIRT3 as part of a stress response to sustain mitochondrial function and to promote the survival of neurons developing tau pathology.

Mitochondria are structurally dynamic organelles and undergo fusion and fission resulting in elongated and smaller mitochondria, respectively. Fusion and fission are implicated in the elimination of abnormal mitochondria by mitophagy [81], maintaining mtDNA integrity [24], regulating mitochondrial morphology [51], and mitochondria distribution within the cell [50]. The central fission protein is the cytosolic DRP1. In 6-mo Tg mice hippocampal cells enriched with tau oligomers, the level of DRP1 was significantly reduced together with mitochondrial elongation linking altered expression of DRP1 to mitochondrial morphology changes early during tau pathology.

DRP1 interacts with hyperphosphorylated tau in $\mathrm{AD}$ brain [53]. Interestingly, reduced DRP1 and increased mitochondrial fusion protected against various tauinduced mitochondrial dysfunction in the cortex and hippocampus of a double mutant P301L tau and DRP1 heterozygous knockout mice [37]. Thus, the reduced DRP1 level and mitochondrial elongation may constitute a key mechanism to maintain mitochondrial homeostasis and to promote cell survival in 6-mo Tg mice CA1 hippocampal neurons. In 12-mo $\mathrm{Tg}$ mice, mitochondrial elongation decreased but persists despite DRP1 returning to Wt levels.
ANT1 transports ADP and ATP across the mitochondrial inner membrane. ANT1-deficient mice do not show overt brain pathology, and ANT1-deficient neurons are resistant to excitotoxicity induced death [49]. Thus, it is possible that the significant reduction in the expression of ANT1 in 6-mo Tg mice CA1 neurons (Fig. 4a) provides a neuroprotective function, maybe as part of a mitochondrial and neuronal stress response to tau oligomers.

The mitochondrial outer membrane protein VDAC1 plays central roles in regulating mitochondrial function and mitochondrial-related apoptosis [11]. VDAC1 has been linked to AD pathogenesis [73] and VDAC1 interaction with hyperphosphorylated tau negatively affected mitochondrial function [54]. The increased concentration of VDAC1 in hyperphoshorylated tau-expressing CA1 neurons in 12-mo $\mathrm{Tg}$ mice, but not in 6-mo $\mathrm{Tg}$ mice, is in line with a previous report showing high expression of VDAC1 in AD brains at advanced stages of the disease and in AD transgenic mouse brain [18]. Overexpression of VDAC1 induces apoptotic cell death in various cell types [90], consistent with the reduced cell density seen in 12-mo Tg CA1 neurons (Fig. 7b).

Thus, our results suggest that most of the neuroprotective stress responses in 6-mo $\mathrm{Tg}$ mice CA1 neurons are transient and effective in the early stages of tau pathology when tau oligomers are abundant. Notably, an adaptive prosurvival response triggered by mitochondrial stress has been recently described in human skeletal muscle cells [56].

8-oxo-G is the major oxidative DNA base lesion and is frequently used as a biomarker of the state of cellular stress and ROS generated DNA damage [22]. OGG1 is the major DNA glycosylase for the removal of 8-oxo-G from DNA [43]. Our results showed increased 8-oxo-G levels together with enhanced OGG1 protein level and 8-oxo-G repair activity in the 6-mo Tg mice CA1 neurons. Thus, we have identified a combination of increased DNA lesions and the activity that repairs those lesions as a novel consequence of tau oligomerization.

Pol $\beta$ deficiency exacerbates AD phenotypes and mitochondrial dysfunction [34, 58, 77], and post- mortem brain extracts from $A D$ patients showed impaired $\operatorname{Pol} \beta$ activity [88]. Pol $\beta$ is the central nuclear BER DNA polymerase in mammalian cells. Mice with targeted disruption of $\operatorname{Pol} \beta$ die shortly after birth [74]. Histological examination of the embryos revealed a key role for Pol $\beta$ in neurogenesis and neuronal development [74]. Pol $\beta$ is predominantly present in the nucleus; however, recently, Pol $\beta$ has also been detected in mitochondria where it contributes to mtDNA integrity $[65,76]$. The localization of $\operatorname{Pol} \beta$ in mitochondria appears to be tissue dependent and controlled by an unknown mechanism, because it was found in mouse brain mitochondria but not in the liver mitochondria [76]. Thus, under normal physiological conditions, Pol $\beta$ is present in 
the brain nuclei and mitochondria. However, the translocation of Pol $\beta$ from the nucleus to mitochondria appears more prominent under cellular stress conditions generated by tau oligomerization (Fig. 6). These results suggest a protective function of mitochondrial localization of Pol $\beta$ in the brain that may involve mtDNA repair [76]. However, other hitherto unknown functions cannot be ruled out and this is an interesting and important subject for investigation. Importantly, this is the first demonstration of mitochondrial localization of Pol $\beta$ in the etiology of tauopathy and AD.

Tau oligomers are thought to be neurotoxic and cause mitochondrial dysfunction [44, 45]. Our results, however, reveal several protective mechanisms, e.g. increased SIRT3 (Fig. 3a), mtDNA copy number (Suppl. Figure 3), BER activity (Fig. 5c and d), and reduced DRP1 and ANT1 levels (Fig. 2d and 4a), in response to tau lesion, probably allowing neurons to prevent irreversible mitochondrial dysfunction and cell death (Fig. 8b). The benefit of these protective mechanisms early in tau pathology might, however, contribute to the long-term survival of neurons expressing tau pathology [59], and in that way contribute to the progression of $\mathrm{AD}$ and related tauopathies.

An important finding in our work is that almost all mitochondrial, as well as DNA damage and repair, phenotypes observed in 6-mo $\mathrm{Tg}$ mice hippocampus were reversed or corrected to the level of Wt mice when the mice were 12 months old. The protective response correlated to the presence of tau oligomers was not a secondary effect of tau overexpression, because the level of tau actually substantially increased over time (Fig. 2d, e).

In human $\mathrm{AD}$ brains, intraneuronal accumulation of soluble tau oligomers correlates with synaptic alterations, neuroinflammation and memory deficits [32, 42, 62]. Notably, synaptic loss, neuroinflammation, and memory deficit, but no cell loss, have been reported in 6 months old THY-Tau22 mice bred in the same lab (66, 44). This suggests that the endogenous soluble tau oligomers have a deleterious effect on neuronal function, unrelated to cell death. Altogether, our results suggest that in 6-mo THY-Tau22 mice, CA1 neurons develop mechanisms to protect against cell toxicity and cell death caused by soluble tau oligomers, but fail to prevent fully soluble tau oligomers from triggering cellular dysfunctions. Cellular alterations elicited by soluble tau oligomers will persist and participate in progressive neuronal dysfunction and behavioral deficits despite the decrease or loss of toxic oligomeric tau at later stages of the pathology (Fig. 8b).

A number of recent studies have investigated various intervention strategies to improve or correct key disease phenotypes in animal models of human neurodegenerative diseases including $\operatorname{AD}[25,26,34]$. These studies have demonstrated mitochondria and DNA damage responses as potentially safe therapeutic targets. It will be interesting to investigate the effect of these drugs on the progression of tau pathology and neuronal stress response in THY-tau22 mouse.

In summary, our data suggests that early during the development of tau pathology, when soluble prefibrillar tau oligomers are prominent and cells undergo stress, CA1 hippocampal neurons activate pro-survival mitochondrial and DNA repair stress responses. However, these protective mechanisms may also allow the progressive accumulation of tau aggregates in affected neurons, and increasing risk of propagation of pathological forms of tau to neighboring neurons over time, as observed in AD. Notably, while extranuclear $\operatorname{Pol} \beta$ in hyperphosphorylated and oligomerized tau overexpressing cells may have a positive effect on mtDNA integrity, it may have a deleterious effect on nuclear BER whereby promoting genomic instability observed in early $\mathrm{AD}[7,72$, 84]. Thus, although soluble tau oligomers represent plausible targets for treatment [12], controlling prosurvival mechanisms as a therapeutic strategy needs careful investigation.

To our knowledge, this work provides the first description of multiple stress responses implicating mitochondrial homeostasis and BER early during the progression of tau pathology and tau oligomerization (Fig. 8). In our view, these results represent an important advance in the etiopathogenesis of tauopathies. We speculate that the activation of pro-survival stress response trigged by tau oligomers contributes to the progressive neuronal dysfunction and the strong age-associated clinical manifestations of tauopathies (Fig. 8a, b). Elucidating the underlying molecular mechanisms that control these events and the consequences of their failure to the progression of tau pathology and neuronal dysfunction warrants investigation.

\section{Supplementary information}

Supplementary information accompanies this paper at https://doi.org/10. 1186/s40478-020-00896-8.

Additional file 1 : Figure S1. Tau pathology does not affect mitochondrial mass in CA1 neurons. WB analysis of extracts from 6-mo $\mathrm{Wt}$ and $\mathrm{Tg}$ mice CA1 (Wt, $n=6 ; \mathrm{Tg}, n=5)(\mathbf{A})$, and from 12-mo Wt and Tg mice hippocampi (Wt, $n=5 ; \mathrm{Tg}, n=6)$ (B) for VDAC1. Actin was used as loading control. Data are presented as mean \pm SEM.

Additional file 2 : Figure S2. Tau pathology does not affect the expression of the key regulator of mitochondrial biogenesis Pgc1a. WB analysis of extracts from 6-mo Wt and Tg mice CA1 (Wt, $n=6 ; \mathrm{Tg}, n=5$ ) (A), and from 12-mo Wt and Tg mice hippocampi (Wt, $n=5$; $\operatorname{Tg}, n=6$ ) (B) for PGC-1a. Actin was used as loading control. Data are presented as mean \pm SEM.

Additional file 3 : Figure S3. Early tau pathology correlates with increased number of mtDNA molecules. (A) Quantitative-PCR analysis of mtDNA copy number was carried out in total DNA isolated from CA1 region from 6-mo Wt $(n=5)$ and $\operatorname{Tg}(n=6)$ mice. Ndl and $16 \mathrm{~s}$ rRNA are mitochondrial genes and $H k 2$ is a nuclear gene. (B) Analysis of mtDNA 
copy number in total DNA from $12-\mathrm{mo} \mathrm{Wt}(n=5)$ and $\mathrm{Tg}(n=5)$ mice hippocampi. Data are presented as mean $\pm \operatorname{SEM}(* P<0.05)$.

Additional file 4 : Figure S4. ATP measurements in 6-mo Tg and Wt CA1. ATP was measured using a luciferase-based assay (ATPlite Luminescence Assay Kit, PerkinElmer), following the Manufacturer's protocol. The content of ATP was normalized to protein content and presented as percentage of control.

Additional file 5 : Figure S5. BER activity is not changed in 12-mo Tg mice. Biochemical analysis of BER activity in hippocampal extracts from 12-mo Tg and Wt mice. (A) AP-site incision activity. Recombinant APE1 protein was used as a positive control. (B) Uracil removal activity. Purified recombinant UNG was used as a positive control. (C) 8-oxo-G removal activity Formamidopyrimidine DNA glycosylase (FPG) was used as a positive control. (D) Polß nucleotide incorporation activity. (E) Quantifications of $A-D$, data are presented as mean \pm SEM.

Additional file $\mathbf{6}$ : Figure S6. Pol $\beta$ protein level is not changed in $\mathrm{Tg}$ mice. WB analysis of extracts from 6 -mo Wt and Tg mice CA1 (Wt, $n=7$; $\mathrm{Tg}, n=6)(\mathbf{A})$, and from 12-mo Wt and Tg mice hippocampi (Wt, $n=5$; $\mathrm{Tg}, n=5)(\mathbf{B})$ for Polß. Actin was used as loading control. Data are presented as mean \pm SEM

Additional file $\mathbf{7}$ : Figure S7. Absence of cytoplasmic accumulation of $\mathrm{Pol} \beta$ in 12 -mo Tg mice hippocampal neurons. Representative images of sagittal CA1 sections from 12-mo Wt and Tg mice hippocampi. The sections were co-labeled with anti-phospho-tau (AT8), and Pol $\beta$ antibodies ( $n=3$ for each mouse category). Immunofluorescence signals were analyzed using laser scanning confocal microscopy (z projection). Nuclei were detected with DAPI staining. Representative nuclei are delimitated by white dashed lines. The scale bars represent $20 \mu \mathrm{m}$. The intensity of the cellular and nuclear Pol $\beta$ fluorescence signals was quantified within CA1 cells from 12-mo Wt and Tg hippocampi (nuclei: Wt, $n=84 ; \mathrm{Tg}, n=$ 66; cellular: Wt, $n=97 ; \mathrm{Tg}, n=98$ ). Graph shows the mean of nuclear fluorescence per mouse category. Data are presented as mean \pm SEM.

Additional file 8 : Figure S8. Increased mitochondrial $P o l \beta$ in Tg mice hippocampal neurons. Representative immunoelectron microscopy images of CA1 sections from 6-mo Tg and Wt mice hippocampus. The sections were labeled with Pol $\beta$ antibodies $(n=3$ for each mouse category). The scale bars represent $100 \mathrm{~nm}$. Red arrows point Pol $\beta$ localization

Additional file 9 : Figure S9. PCR-based mtDNA damage analysis. (A) MtDNA damage analysis from 6 -mo Wt $(n=5)$ and $\mathrm{Tg}(n=6)$ mice CA region by long range PCR. (B) MtDNA analysis of 12-mo Wt $(n=5)$ and $\operatorname{Tg}(n=5)$ mice hippocampi. Data are presented as mean \pm SEM. Statistics were performed with unpaired two-tailed Mann-Whitney test (**P $<0.01$ )

Additional file 10 : Figure S10. Schematic representation of a coronal mouse hippocampal section. The dashed red line shows the dissected CA1 region.

Additional file 11 : Figure S11. Increased cytoplasmic and mitochondrial accumulation of PolB in neurons from AD brain. Representative images of frontal cortex sections from human control (Ctr) and Braak VI Alzheimer (AD) frontal cortex. Immunofluorescence signals were analyzed by laser scanning confocal microscopy. Nuclei were detected with DAPI staining. The scale bars represent $20 \mu \mathrm{m}$. (A) The sections were labeled with the tau oligomer antibody, TOC1, and antiPol $\beta$ antibody ( $n=3$ for each category) ( $z$ projection) or (B) with antibodies against Pol $\beta$ and VDAC1 (single confocale section).

Additional file 12 : Figure S12. List of oligonucleotides used in mtDNA analysis and in BER assays.

\section{Acknowledgments}

We are grateful to IMPRT (Institut de Médecine Prédictive et de Recherche Thérapeutique, Lille, France) for access to the confocal microscopy platform and the animal facility. We thank M. Besegher, J. Devassine, and D. Blum for animal care and management. We thank Louis-Adrien Pécherau and Nicolas Delettre for technical assistance. We are grateful to M. Tardivel and A. Bongiovanni for their assistance with confocal microscopy analyses. We thank Beverly Baptiste and Xiuli Dan for critical reading of the manuscript. We thank Susanna Schraen for fruitful discussion. We express gratitude to
Alzheimer's disease patients and their families who allowed us to perform brain autopsies.

This work was supported by NORDEA Foundation, Denmark (02-2013-0220); Innovation Fund Denmark (5188-00001); Olav Thon foundation Norway (531811-710131); Novo Nordisk foundation Denmark (NNF17OC0027812); LabEx (Excellence Laboratory) - Development of Innovative Strategies for a Transdisciplinary Approach to Alzheimer's Disease [DISTALZ]. V.A.B and M-C.G are also supported by INSTALZ, an EU Joint Programme - Neurodegenerative Disease Research (JPND) project. The INSTALZ project is supported through the following funding organisations under the aegis of JPND - "http://www. jpnd.eu" (Belgium, Research Foundation Flanders; Denmark, Innovation Fund Denmark; France, Agence Nationale de la Recherche; Sweden, Swedish Research Council; United Kingdom, Medical Research Council). The project has received funding from the European Union's Horizon 2020 research and innovation programme under grant agreement No 643417. This work was also supported, in part, by the intramural research program at the National Institutes of Health, National Institute on Aging.

\section{Authors' contributions}

$J Z, M C G, C S, M L R, A L, B L$, and MA performed experiments and analyzed data. $\checkmark A B, M C G$ and MA designed the project, analyzed data, and prepared the manuscript. LB and DLC discussed the results and helped with writing the manuscript. VAB and MCG supervised the project. All authors read and approved the final manuscript.

\section{Competing interests}

The authors declare no financial or competing interests.

\section{Author details}

${ }^{1}$ Center for Healthy Aging, Department of Cellular and Molecular Medicine, SUND, University of Copenhagen, 2200 Copenhagen N, Denmark. ${ }^{2}$ University of Lille, Inserm, CHU Lille, UMR-S 1172 - Lille Neuroscience \& Cognition, F-59000 Lille, France. ${ }^{3}$ Laboratory of Molecular Gerontology, National Institute on Aging, NIH, 251 Bayview Blvd, Suite 100, Rm 06B133, Baltimore, MD 21224, USA

Received: 8 February 2020 Accepted: 11 February 2020

Published online: 04 March 2020

\section{References}

1. Akbari M, Kirkwood TBL, Bohr VA (2019) Mitochondria in the signaling pathways that control longevity and health span. Ageing Res Rev 54: 100940. https://doi.org/10.1016/j.arr.2019.100940

2. Akbari M, Krokan HE (2008) Cytotoxicity and mutagenicity of endogenous DNA base lesions as potential cause of human aging. Mech Ageing Dev 129:353-365. https://doi.org/10.1016/.mad.2008.01.007

3. Akbari M, Sykora P, Bohr VA (2015) Slow mitochondrial repair of 5'-AMP renders mtDNA susceptible to damage in APTX deficient cells. Sci Rep 5: 12876. https://doi.org/10.1038/srep12876

4. Akbari M, Visnes T, Krokan HE, Otterlei M (2008) Mitochondrial base excision repair of uracil and AP sites takes place by single-nucleotide insertion and long-patch DNA synthesis. DNA repair 7:605-616. https://doi.org/10.1016/j. dnarep.2008.01.002

5. Arendt T, Stieler JT, Holzer M (2016) Tau and tauopathies. Brain Res Bull 126 238-292. https://doi.org/10.1016/j.brainresbull.2016.08.018

6. Benhelli-Mokrani H, Mansuroglu Z, Chauderlier A, Albaud B, Gentien D, Sommer S, Schirmer C, Laqueuvre L, Josse T, Buee L et al (2018) Genomewide identification of genic and intergenic neuronal DNA regions bound by tau protein under physiological and stress conditions. Nucleic Acids Res 46: 11405-11422. https://doi.org/10.1093/nar/gky929

7. Bradley-Whitman MA, Timmons MD, Beckett TL, Murphy MP, Lynn BC, Lovell MA (2014) Nucleic acid oxidation: an early feature of Alzheimer's disease. J Neurochem 128:294-304. https://doi.org/10.1111/jnc.12444

8. Brand MD, Pakay JL, Ocloo A, Kokoszka J, Wallace DC, Brookes PS, Cornwall EJ (2005) The basal proton conductance of mitochondria depends on adenine nucleotide translocase content. Biochem J 392:353-362. https://doi. org/10.1042/BJ20050890

9. Brown TA, Tkachuk AN, Shtengel G, Kopek BG, Bogenhagen DF, Hess HF, Clayton DA (2011) Superresolution fluorescence imaging of mitochondrial nucleoids reveals their spatial range, limits, and membrane interaction. Mol Cell Biol 31:4994-5010. https://doi.org/10.1128/MCB.05694-11 
10. Cadenas E, Davies KJ (2000) Mitochondrial free radical generation, oxidative stress, and aging. Free Radic Biol Med 29:222-230

11. Camara AKS, Zhou Y, Wen PC, Tajkhorshid E, Kwok WM (2017) Mitochondrial VDAC1: a key gatekeeper as potential therapeutic target. Front Physiol 8: 460. https://doi.org/10.3389/fphys.2017.00460

12. Castillo-Carranza DL, Gerson JE, Sengupta U, Guerrero-Munoz MJ, LasagnaReeves CA, Kayed R (2014) Specific targeting of tau oligomers in Htau mice prevents cognitive impairment and tau toxicity following injection with brain-derived tau oligomeric seeds. J Alzheimers Dis 40(Suppl 1):S97-S111. https://doi.org/10.3233/JAD-132477

13. Chan DC (2012) Fusion and fission: interlinked processes critical for mitochondrial health. Annu Rev Genet 46:265-287. https://doi.org/10.1146/ annurev-genet-1 10410-132529

14. Chen Y, Zhang J, Lin Y, Lei Q, Guan KL, Zhao S, Xiong Y (2011) Tumour suppressor SIRT3 deacetylates and activates manganese superoxide dismutase to scavenge ROS. EMBO Rep 12:534-541. https://doi.org/10.1038/ embor.2011.65

15. Cheng A, Yang Y, Zhou Y, Maharana C, Lu D, Peng W, Liu Y, Wan R, Marosi K, Misiak M et al (2016) Mitochondrial SIRT3 mediates adaptive responses of neurons to exercise and metabolic and excitatory challenges. Cell Metab 23: 128-142. https://doi.org/10.1016/j.cmet.2015.10.013

16. Clay Montier LL, Deng JJ, Bai Y (2009) Number matters: control of mammalian mitochondrial DNA copy number. J Genet Genomics 36:125131. https://doi.org/10.1016/S1673-8527(08)60099-5

17. Cogliati S, Frezza C, Soriano ME, Varanita T, Quintana-Cabrera R, Corrado M, Cipolat S, Costa V, Casarin A, Gomes LC et al (2013) Mitochondrial cristae shape determines respiratory chain supercomplexes assembly and respiratory efficiency. Cell 155:160-171. https://doi.org/10.1016/j.cell.2013.08. 032

18. Cuadrado-Tejedor M, Vilarino M, Cabodevilla F, Del Rio J, Frechilla D, PerezMediavilla A (2011) Enhanced expression of the voltage-dependent anion channel 1 (VDAC1) in Alzheimer's disease transgenic mice: an insight into the pathogenic effects of amyloid-beta. J Alzheimers Dis 23:195-206. https://doi.org/10.3233/JAD-2010-100966

19. Czabotar PE, Lessene G, Strasser A, Adams JM (2014) Control of apoptosis by the BCL-2 protein family: implications for physiology and therapy. Nat Rev Mol Cell Biol 15:49-63. https://doi.org/10.1038/nrm3722

20. D'Amelio M, Cavallucci V, Middei S, Marchetti C, Pacioni S, Ferri A, Diamantini A, De Zio D, Carrara P, Battistini L et al (2011) Caspase-3 triggers early synaptic dysfunction in a mouse model of Alzheimer's disease. Nat Neurosci 14:69-76. https://doi.org/10.1038/nn.2709

21. Dai SH, Chen T, Wang YH, Zhu J, Luo P, Rao W, Yang YF, Fei Z, Jiang XF (2014) Sirt3 protects cortical neurons against oxidative stress via regulating mitochondrial $\mathrm{Ca} 2+$ and mitochondrial biogenesis. Int J Mol Sci 15:1459114609. https://doi.org/10.3390/ijms150814591

22. Dizdaroglu M, Jaruga P (2012) Mechanisms of free radical-induced damage to DNA. Free Radic Res 46:382-419. https://doi.org/10.3109/10715762.2011. 653969

23. Drago I, De Stefani D, Rizzuto R, Pozzan T (2012) Mitochondrial Ca2+ uptake contributes to buffering cytoplasmic Ca2+ peaks in cardiomyocytes. Proc Natl Acad Sci U S A 109:12986-12991. https://doi.org/10.1073/pnas. 1210718109

24. Elachouri G, Vidoni S, Zanna C, Pattyn A, Boukhaddaoui H, Gaget K, Yu-WaiMan P, Gasparre G, Sarzi E, Delettre C et al (2011) OPA1 links human mitochondrial genome maintenance to mtDNA replication and distribution. Genome Res 21:12-20. https://doi.org/10.1101/gr.108696.110

25. Fang EF, Hou Y, Palikaras K, Adriaanse BA, Kerr JS, Yang B, Lautrup S, HasanOlive MM, Caponio D, Dan X et al (2019) Mitophagy inhibits amyloid-beta and tau pathology and reverses cognitive deficits in models of Alzheimer's disease. Nat Neurosci 22:401-412. https://doi.org/10.1038/s41593-018-0332-9

26. Fang EF, Kassahun H, Croteau DL, Scheibye-Knudsen M, Marosi K, Lu H, Shamanna RA, Kalyanasundaram S, Bollineni RC, Wilson MA et al (2016) $\mathrm{NAD}(+)$ replenishment improves lifespan and healthspan in ataxia telangiectasia models via mitophagy and DNA repair. Cell Metab 24:566581. https://doi.org/10.1016/j.cmet.2016.09.004

27. Fang EF, Scheibye-Knudsen M, Brace LE, Kassahun H, SenGupta T, Nilsen H, Mitchell JR, Croteau DL, Bohr VA (2014) Defective mitophagy in XPA via PARP-1 hyperactivation and NAD(+)/SIRT1 reduction. Cell 157:882-896. https://doi.org/10.1016/j.cell.2014.03.026

28. Farge G, Falkenberg M (2019) Organization of DNA in mammalian mitochondria. Int J Mol Sci 20. https://doi.org/10.3390/ijms20112770
29. Flach K, Hilbrich I, Schiffmann A, Gartner U, Kruger M, Leonhardt M, Waschipky H, Wick L, Arendt T, Holzer M (2012) Tau oligomers impair artificial membrane integrity and cellular viability. J Biol Chem 287:4322343233. https://doi.org/10.1074/jbc. M112.396176

30. Fuke S, Kubota-Sakashita M, Kasahara T, Shigeyoshi Y, Kato T (2011) Regional variation in mitochondrial DNA copy number in mouse brain. Biochim Biophys Acta 1807:270-274. https://doi.org/10.1016/j.bbabio.2010.11.016

31. Galluzzi L, Baehrecke EH, Ballabio A, Boya P, Bravo-San Pedro JM, Cecconi F, Choi AM, Chu CT, Codogno P, Colombo Ml et al (2017) Molecular definitions of autophagy and related processes. EMBO J 36:1811-1836. https://doi.org/10.15252/embj.201796697

32. Guerrero-Munoz MJ, Gerson J, Castillo-Carranza DL (2015) Tau oligomers: the toxic player at synapses in Alzheimer's disease. Front Cell Neurosci 9: 464. https://doi.org/10.3389/fncel.2015.00464

33. Hosseini-Sharifabad M, Nyengaard JR (2007) Design-based estimation of neuronal number and individual neuronal volume in the rat hippocampus. J Neurosci Methods 162:206-214. https://doi.org/10.1016/j.jneumeth.2007.01.009

34. Hou Y, Lautrup S, Cordonnier S, Wang Y, Croteau DL, Zavala E, Zhang Y, Moritoh K, O'Connell JF, Baptiste BA et al (2018) NAD(+) supplementation normalizes key Alzheimer's features and DNA damage responses in a new AD mouse model with introduced DNA repair deficiency. Proc Natl Acad Sci U S A 115:E1876-E1885. https://doi.org/10.1073/pnas.1718819115

35. Jager S, Handschin C, St-Pierre J, Spiegelman BM (2007) AMP-activated protein kinase (AMPK) action in skeletal muscle via direct phosphorylation of PGC-1alpha. Proc Natl Acad Sci U S A 104:12017-12022. https://doi.org/ 10.1073/pnas.0705070104

36. Jin SM, Lazarou M, Wang C, Kane LA, Narendra DP, Youle RJ (2010) Mitochondrial membrane potential regulates PINK1 import and proteolytic destabilization by PARL. J Cell Biol 191:933-942. https://doi.org/10.1083/jcb. 201008084

37. Kandimalla R, Manczak M, Fry D, Suneetha Y, Sesaki H, Reddy PH (2016) Reduced dynamin-related protein 1 protects against phosphorylated tauinduced mitochondrial dysfunction and synaptic damage in Alzheimer's disease. Hum Mol Genet 25:4881-4897. https://doi.org/10.1093/hmg/ ddw312

38. Kaniyappan S, Chandupatla RR, Mandelkow EM, Mandelkow E (2017) Extracellular low-n oligomers of tau cause selective synaptotoxicity without affecting cell viability. Alzheimers Dement 13:1270-1291. https://doi.org/10. 1016/j.jalz.2017.04.002

39. Kim SH, Lu HF, Alano CC (2011) Neuronal Sirt3 protects against excitotoxic injury in mouse cortical neuron culture. PLoS One 6:e14731. https://doi.org/ 10.1371/journal.pone.0014731

40. Klionsky DJ, Abdelmohsen K, Abe A, Abedin MJ, Abeliovich H, Acevedo Arozena A, Adachi H, Adams CM, Adams PD, Adeli K et al (2016) Guidelines for the use and interpretation of assays for monitoring autophagy (3rd edition). Autophagy 12:1-222. https://doi.org/10.1080/15548627.2015. 1100356

41. Kondadi AK, Wang S, Montagner S, Kladt N, Korwitz A, Martinelli P, Herholz D, Baker MJ, Schauss AC, Langer T et al (2014) Loss of the m-AAA protease subunit $A F G(3) L(2)$ causes mitochondrial transport defects and tau hyperphosphorylation. EMBO J 33:1011-1026. https://doi.org/10.1002/embj. 201387009

42. Koss DJ, Jones G, Cranston A, Gardner H, Kanaan NM, Platt B (2016) Soluble pre-fibrillar tau and beta-amyloid species emerge in early human Alzheimer's disease and track disease progression and cognitive decline. Acta Neuropathol 132:875-895. https://doi.org/10.1007/s00401-016-1632-3

43. Krokan HE, Bjoras M (2013) Base excision repair. Cold Spring Harb Perspect Biol 5:a012583. https://doi.org/10.1101/cshperspect.a012583

44. Lasagna-Reeves CA, Castillo-Carranza DL, Guerrero-Muoz MJ, Jackson GR, Kayed R (2010) Preparation and characterization of neurotoxic tau oligomers. Biochemistry 49:10039-10041. https://doi.org/10.1021/bi1016233

45. Lasagna-Reeves CA, Castillo-Carranza DL, Sengupta U, Clos AL, Jackson GR, Kayed R (2011) Tau oligomers impair memory and induce synaptic and mitochondrial dysfunction in wild-type mice. Mol Neurodegener 6:39. https://doi.org/10.1186/1750-1326-6-39

46. Lasagna-Reeves CA, Castillo-Carranza DL, Sengupta U, Sarmiento J, Troncoso J, Jackson GR, Kayed R (2012) Identification of oligomers at early stages of tau aggregation in Alzheimer's disease. FASEB J 26:1946-1959. https://doi. org/10.1096/fj.11-199851

47. Laurent C, Burnouf S, Ferry B, Batalha VL, Coelho JE, Baqi Y, Malik E, Marciniak E, Parrot S, Van der Jeugd A et al (2016) A2A adenosine receptor 
deletion is protective in a mouse model of tauopathy. Mol Psychiatry 21: 149. https://doi.org/10.1038/mp.2015.115

48. Lee J, Kim Y, Liu T, Hwang YJ, Hyeon SJ, Im H, Lee K, Alvarez VE, McKee AC, Um SJ et al (2018) SIRT3 deregulation is linked to mitochondrial dysfunction in Alzheimer's disease. Aging Cell 17. https://doi.org/10.1111/acel.12679

49. Lee J, Schriner SE, Wallace DC (2009) Adenine nucleotide translocator 1 deficiency increases resistance of mouse brain and neurons to excitotoxic insults. Biochim Biophys Acta 1787:364-370. https://doi.org/10.1016/j.bbabio. 2009.01.014

50. Li Z, Okamoto K, Hayashi Y, Sheng M (2004) The importance of dendritic mitochondria in the morphogenesis and plasticity of spines and synapses. Cell 119:873-887. https://doi.org/10.1016/j.cell.2004.11.003

51. Liao C, Ashley N, Diot A, Morten K, Phadwal K, Williams A, Fearnley I, Rosser L, Lowndes J, Fratter C et al (2017) Dysregulated mitophagy and mitochondrial organization in optic atrophy due to OPA1 mutations. Neurology 88:131-142. https://doi.org/10.1212/WNL.0000000000003491

52. Lombard DB, Alt FW, Cheng HL, Bunkenborg J, Streeper RS, Mostoslavsky R, Kim J, Yancopoulos G, Valenzuela D, Murphy A et al (2007) Mammalian Sir2 homolog SIRT3 regulates global mitochondrial lysine acetylation. Mol Cell Biol 27:8807-8814. https://doi.org/10.1128/MCB.01636-07

53. Manczak M, Reddy PH (2012) Abnormal interaction between the mitochondrial fission protein Drp1 and hyperphosphorylated tau in Alzheimer's disease neurons: implications for mitochondrial dysfunction and neuronal damage. Hum Mol Genet 21:2538-2547. https://doi.org/10.1093/ hmg/dds072

54. Manczak M, Reddy PH (2012) Abnormal interaction of VDAC1 with amyloid beta and phosphorylated tau causes mitochondrial dysfunction in Alzheimer's disease. Hum Mol Genet 21:5131-5146. https://doi.org/10.1093/ hmg/dds360

55. Marcus JM, Andrabi SA (2018) SIRT3 regulation under cellular stress: making sense of the ups and downs. Front Neurosci 12:799. https://doi.org/10.3389/ fnins.2018.00799

56. Mayorga L, Salassa BN, Marzese DM, Loos MA, Eiroa HD, Lubieniecki F, Garcia Samartino C, Romano PS, Roque M (2019) Mitochondrial stress triggers a pro-survival response through epigenetic modifications of nuclear DNA. Cell Mol Life Sci 76:1397-1417. https://doi.org/10.1007/s00018-01903008-5

57. Merkwirth C, Martinelli P, Korwitz A, Morbin M, Bronneke HS, Jordan SD, Rugarli El, Langer T (2012) Loss of prohibitin membrane scaffolds impairs mitochondrial architecture and leads to tau hyperphosphorylation and neurodegeneration. PLoS Genet 8:e1003021. https://doi.org/10.1371/journal. pgen.1003021

58. Misiak M, Vergara Greeno R, Baptiste BA, Sykora P, Liu D, Cordonnier S, Fang EF, Croteau DL, Mattson MP, Bohr VA (2017) DNA polymerase beta decrement triggers death of olfactory bulb cells and impairs olfaction in a mouse model of Alzheimer's disease. Aging Cell 16:162-172. https://doi.org/ 10.1111/acel.1254

59. Morsch R, Simon W, Coleman PD (1999) Neurons may live for decades with neurofibrillary tangles. J Neuropathol Exp Neurol 58:188-197. https://doi. org/10.1097/00005072-199902000-00008

60. Mufson EJ, Ward S, Binder L (2014) Prefibrillar tau oligomers in mild cognitive impairment and Alzheimer's disease. Neurodegener Dis 13:151153. https://doi.org/10.1159/000353687

61. Nemoto S, Fergusson MM, Finkel T (2005) SIRT1 functionally interacts with the metabolic regulator and transcriptional coactivator PGC-1\{alpha\}. J Biol Chem 280:16456-16460. https://doi.org/10.1074/jbc. M501485200

62. Nilson AN, English KC, Gerson JE, Barton Whittle T, Nicolas Crain C, Xue J, Sengupta U, Castillo-Carranza DL, Zhang W, Gupta P et al (2017) Tau oligomers associate with inflammation in the brain and retina of tauopathy mice and in neurodegenerative diseases. J Alzheimers Dis 55:1083-1099. https://doi.org/10.3233/JAD-160912

63. Ozkurede U, Miller RA (2019) Improved mitochondrial stress response in long-lived snell dwarf mice. Aging cell:e13030. https://doi.org/10.1111/acel. 13030

64. Patterson KR, Remmers C, Fu Y, Brooker S, Kanaan NM, Vana L, Ward S, Reyes JF, Philibert K, Glucksman MJ et al (2011) Characterization of prefibrillar tau oligomers in vitro and in Alzheimer disease. J Biol Chem 286: 23063-23076. https://doi.org/10.1074/jbc. M111.237974

65. Prasad R, Caglayan M, Dai DP, Nadalutti CA, Zhao ML, Gassman NR, Janoshazi AK, Stefanick DF, Horton JK, Krasich R et al (2017) DNA polymerase beta: a missing link of the base excision repair machinery in mammalian mitochondria. DNA Repair 60:77-88. https://doi.org/10.1016/j. dnarep.2017.10.011

66. Qu J, Wu YX, Zhang T, Qiu Y, Ding ZJ, Zha DJ (2018) Sirt3 confers protection against acrolein-induced oxidative stress in cochlear nucleus neurons. Neurochem Int 114:1-9. https://doi.org/10.1016/j.neuint.2017.12.004

67. Rahman A, Grundke-labal I, labal K (2005) Phosphothreonine-212 of Alzheimer abnormally hyperphosphorylated tau is a preferred substrate of protein phosphatase-1. Neurochem Res 30:277-287

68. Santos JH, Mandavilli BS, Van Houten B (2002) Measuring oxidative mtDNA damage and repair using quantitative PCR. Methods Mol Biol 197:159-176. https://doi.org/10.1385/1-59259-284-8:159

69. Scarpulla RC (2011) Metabolic control of mitochondrial biogenesis through the PGC-1 family regulatory network. Biochim Biophys Acta 1813:1269-1278. https://doi.org/10.1016/j.bbamcr.2010.09.019

70. Schindowski K, Bretteville A, Leroy K, Begard S, Brion JP, Hamdane M, Buee $L$ (2006) Alzheimer's disease-like tau neuropathology leads to memory deficits and loss of functional synapses in a novel mutated tau transgenic mouse without any motor deficits. Am J Pathol 169:599-616. https://doi. org/10.2353/ajpath.2006.060002

71. Sebastian D, Palacin M, Zorzano A (2017) Mitochondrial dynamics: coupling mitochondrial fitness with healthy aging. Trends Mol Med 23:201-215. https://doi.org/10.1016/j.molmed.2017.01.003

72. Shanbhag NM, Evans MD, Mao W, Nana AL, Seeley WW, Adame A, Rissman RA, Masliah E, Mucke L (2019) Early neuronal accumulation of DNA double strand breaks in Alzheimer's disease. Acta Neuropathol Commun 7:77. https://doi.org/10.1186/s40478-019-0723-5

73. Shoshan-Barmatz V, Nahon-Crystal E, Shteinfer-Kuzmine A, Gupta R (2018) VDAC1, mitochondrial dysfunction, and Alzheimer's disease. Pharmacol Res 131:87-101. https://doi.org/10.1016/j.phrs.2018.03.010

74. Sugo N, Aratani Y, Nagashima Y, Kubota Y, Koyama H (2000) Neonatal lethality with abnormal neurogenesis in mice deficient in DNA polymerase beta. EMBO J 19:1397-1404. https://doi.org/10.1093/emboj/19.6.1397

75. Swerdlow RH, Burns JM, Khan SM (2014) The Alzheimer's disease mitochondrial cascade hypothesis: progress and perspectives. Biochim Biophys Acta 1842:1219-1231. https://doi.org/10.1016/j.bbadis.2013.09.010

76. Sykora P, Kanno S, Akbari M, Kulikowicz T, Baptiste BA, Leandro GS, Lu H, Tian J, May A, Becker KA et al (2017) DNA polymerase beta participates in mitochondrial DNA repair. Mol Cell Biol. https://doi.org/10.1128/MCB.0023717

77. Sykora P, Misiak M, Wang Y, Ghosh S, Leandro GS, Liu D, Tian J, Baptiste BA, Cong WN, Brenerman BM et al (2015) DNA polymerase beta deficiency leads to neurodegeneration and exacerbates Alzheimer disease phenotypes. Nucleic Acids Res 43:943-959. https://doi.org/10.1093/nar/gku1356

78. Sykora P, Wilson DM 3rd, Bohr VA (2012) Repair of persistent strand breaks in the mitochondrial genome. Mech Ageing Dev 133:169-175. https://doi. org/10.1016/j.mad.2011.11.003

79. Taguchi N, Ishihara N, Jofuku A, Oka T, Mihara K (2007) Mitotic phosphorylation of dynamin-related GTPase Drp1 participates in mitochondrial fission. J Biol Chem 282:11521-11529. https://doi.org/10.1074/ jbc. M607279200

80. Tao R, Coleman MC, Pennington JD, Ozden O, Park SH, Jiang H, Kim HS, Flynn CR, Hill S, Hayes McDonald W et al (2010) Sirt3-mediated deacetylation of evolutionarily conserved lysine 122 regulates MnSOD activity in response to stress. Mol Cell 40:893-904. https://doi.org/10.1016/j. molcel.2010.12.013

81. Twig G, Elorza A, Molina AJ, Mohamed H, Wikstrom JD, Walzer G, Stiles L, Haigh SE, Katz S, Las G et al (2008) Fission and selective fusion govern mitochondrial segregation and elimination by autophagy. EMBO J 27:433446. https://doi.org/10.1038/sj.emboj.7601963

82. Van der Jeugd A, Vermaercke B, Derisbourg M, Lo AC, Hamdane M, Blum D, Buee L, D'Hooge R (2013) Progressive age-related cognitive decline in tau mice. J Alzheimers Dis 37:777-788. https://doi.org/10.3233/JAD-130110

83. van Loo G, Saelens X, van Gurp M, MacFarlane M, Martin SJ, Vandenabeele $P$ (2002) The role of mitochondrial factors in apoptosis: a Russian roulette with more than one bullet. Cell Death Differ 9:1031-1042. https://doi.org/10. 1038/sj.cdd. 4401088

84. Violet M, Chauderlier A, Delattre L, Tardivel M, Chouala MS, Sultan A, Marciniak E, Humez S, Binder L, Kayed R et al (2015) Prefibrillar tau oligomers alter the nucleic acid protective function of tau in hippocampal neurons in vivo. Neurobiol Dis 82:540-551. https://doi.org/10.1016/j.nbd. 2015.09.003 
85. Wang Y, Mandelkow E (2016) Tau in physiology and pathology. Nat Rev Neurosci 17:5-21. https://doi.org/10.1038/nrn.2015.1

86. Ward SM, Himmelstein DS, Lancia JK, Fu Y, Patterson KR, Binder LI (2013) TOC1: characterization of a selective oligomeric tau antibody. J Alzheimers Dis 37:593-602. https://doi.org/10.3233/JAD-131235

87. Weinert BT, Moustafa T, lesmantavicius V, Zechner R, Choudhary C (2015) Analysis of acetylation stoichiometry suggests that SIRT3 repairs nonenzymatic acetylation lesions. EMBO J 34:2620-2632. https://doi.org/10. 15252/embj.201591271

88. Weissman L, Jo DG, Sorensen MM, de Souza-Pinto NC, Markesbery WR, Mattson MP, Bohr VA (2007) Defective DNA base excision repair in brain from individuals with Alzheimer's disease and amnestic mild cognitive impairment. Nucleic Acids Res 35:5545-5555. https://doi.org/10.1093/nar/ gkm605

89. Yoshiyama Y, Higuchi M, Zhang B, Huang SM, Iwata N, Saido TC, Maeda J, Suhara T, Trojanowski JQ, Lee VM (2007) Synapse loss and microglial activation precede tangles in a P301S tauopathy mouse model. Neuron 53: 337-351. https://doi.org/10.1016/j.neuron.2007.01.010

90. Zaid H, Abu-Hamad S, Israelson A, Nathan I, Shoshan-Barmatz V (2005) The voltage-dependent anion channel-1 modulates apoptotic cell death. Cell Death Differ 12:751-760. https://doi.org/10.1038/sj.cdd.4401599

91. Zhang L, Trushin S, Christensen TA, Bachmeier BV, Gateno B, Schroeder A, Yao J, Itoh K, Sesaki H, Poon WW et al (2016) Altered brain energetics induces mitochondrial fission arrest in Alzheimer's disease. Sci Rep 6:18725. https://doi.org/10.1038/srep18725

92. Zheng J, Croteau DL, Bohr VA, Akbari M (2019) Diminished OPA1 expression and impaired mitochondrial morphology and homeostasis in Aprataxindeficient cells. Nucleic Acids Res. https://doi.org/10.1093/nar/gkz083

93. Zick M, Rabl R, Reichert AS (2009) Cristae formation-linking ultrastructure and function of mitochondria. Biochim Biophys Acta 1793:5-19. https://doi. org/10.1016/j.bbamcr.2008.06.013

\section{Publisher's Note}

Springer Nature remains neutral with regard to jurisdictional claims in published maps and institutional affiliations.

Ready to submit your research? Choose BMC and benefit from:

- fast, convenient online submission

- thorough peer review by experienced researchers in your field

- rapid publication on acceptance

- support for research data, including large and complex data types

- gold Open Access which fosters wider collaboration and increased citations

- maximum visibility for your research: over $100 \mathrm{M}$ website views per year

At $\mathrm{BMC}$, research is always in progress.

Learn more biomedcentral.com/submissions 